\title{
Therapeutic implications of cellular and molecular biology of cancer stem cells in melanoma
}

\author{
Dhiraj Kumar ${ }^{1}$, Mahadeo Gorain ${ }^{1}$, Gautam Kundu² and Gopal C. Kundu*
}

\begin{abstract}
Melanoma is a form of cancer that initiates in melanocytes. Melanoma has multiple phenotypically distinct subpopulation of cells, some of them have embryonic like plasticity which are involved in self-renewal, tumor initiation, metastasis and progression and provide reservoir of therapeutically resistant cells. Cancer stem cells (CSCs) can be identified and characterized based on various unique cell surface and intracellular markers. CSCs exhibit different molecular pattern with respect to non-CSCs. They maintain their stemness and chemoresistant features through specific signaling cascades. CSCs are weak in immunogenicity and act as immunosupressor in the host system. Melanoma treatment becomes difficult and survival is greatly reduced when the patient develop metastasis. Standard conventional oncology treatments such as chemotherapy, radiotherapy and surgical resection are only responsible for shrinking the bulk of the tumor mass and tumor tends to relapse. Thus, targeting CSCs and their microenvironment niche addresses the alternative of traditional cancer therapy. Combined use of CSCs targeted and traditional therapies may kill the bulk tumor and CSCs and offer a promising therapeutic strategy for the management of melanoma.
\end{abstract}

Keywords: CSCs, Signaling, Microenvironment, Angiogenesis, Metastasis, Melanoma growth

\section{Background}

Tumor initiating cells having stem cell characteristics were first discovered in leukaemia and later in solid tumors which recently has become an important area in cancer research [1]. These stem like tumor cells, termed as cancer stem cells (CSCs) govern tumor progression, angiogenesis and metastasis via modulating certain specific pathways which depends upon the type of the tissue. CSCs have similar physiological properties as normal stem cells, like self-renewal, differentiation and indefinite proliferation ability which might be the main cause of tumor progression [1]. Conventional anticancer treatments eradicate bulk of tumor mass but it is ineffective for CSCs and hence could be the reason for tumor reoccurrence and progression. CSCs have been identified in hematopoietic cancer and solid tumors like

\footnotetext{
* Correspondence: kundu@nccs.res.in

${ }^{1}$ Laboratory of Tumor Biology, Angiogenesis and Nanomedicine Research,

National Centre for Cell Science (NCCS), Pune411007India

Full list of author information is available at the end of the article
}

brain, breast, prostrate, colon, pancreatic, lung and most recently in melanoma.

Malignant melanoma is a highly aggressive and drugresistant cancer [2]. Several groups have shown the existence of tumor heterogeneity with undifferentiated molecular signatures having high tumorigenic potential with embryonic-like differentiation which strongly suggest the presence and the involvement of CSCs in melanoma. Although the concept of CSCs is well accepted for many tumors, but the existence of CSCs in melanoma has been the subject of debate. Initially, Fang et al. and Monzani et al. have shown the existence of stem cell-like subpopulation in $\mathrm{CD}_{20}{ }^{+}$and $\mathrm{CD} 133^{+}$melanoma cells $[3,4]$. Subsequent studies support the involvement of CSCs in human melanoma progression using $\mathrm{ABCB} 5$ and $\mathrm{CD} 271$ as markers [5, 6]. Recently, Luo et al. have provided significant evidence and shown the existence of CSCs in melanoma by using ALDH, an intercellular stem cell marker in melanoma [7]. Moreover, CSCs are responsible for EMT, metastasis and angiogenesis in autocrine or paracrine manner $[8,9]$. Tumor microenvironment also plays a 
major role during the melanoma progression. For example, stroma-derived osteopontin regulates the side population (SP) enrichment and controls angiogenesis and metastasis in melanoma [10]. Hypoxia inducible factor (HIF) and transcription factor like Snail are expressed in CSCs derived from glioma and melanoma that leads to enrichment of CSC, self-renewal and differentiation and control angiogenesis and metastasis $[11,12]$. CSCs are responsible for recurrence in most of tumor which associated with modulation of tumor microenvironment and immune escape mechanisms [13]. Many studies showed that CSCs exhibit specific intracellular molecular properties that are distinct with their rest of the bulk tumor cells which lead to limited response against conventional treatments $[14,15]$. Additionally, the expression of various miRNAs in CSCs strongly correlates with melanoma progression which helps in the modulation of tumor microenvironment through targeting the various specific signaling pathway [16-18]. Traditional chemotherapy or radiation therapies are not sufficient to eliminate CSCs from the tumors, therefore, understanding the cellular and molecular biology of CSCs are essential for the identification of novel CSCs-targeted therapies.

\section{Melanoma CSCs and their unique markers}

Several lines of evidences suggested the presence and involvement of CSCs in melanoma initiation and progression [3]. Identification of highly aggressive undifferentiated subpopulations with embryonic-like plasticity within the melanoma has established the link between the tumor progression and CSCs [3, 4]. The melanoma derived spheres demonstrated a significant differentiation potential capable of giving rise to melanocytes, adipocytes, osteocytes and chondrocytes. These spheres also exhibit high self-renewal ability both in vitro and in vivo [3]. CSCs are thought to express cell surface and intracellular markers traditionally associated with tissue specific stem cells which are responsible for tumor heterogeneity [19]. Earlier studies suggested that melanoma stem cells can be characterized based on the expression of markers such as CD20, CD133 and MDR1 as shown in Table 1. However, a firm correlation between expression of markers with various other properties such as self-renewal ability, high tumorigenic potential, multilineage differentiation in CSCs is yet to be studied [3-5].

Previous studies demonstrate that melanoma cells or clinical specimens undergoing chemoresistance overexpress a number of stem cell markers including CD133 and ABCG2 [4]. Furthermore, Nordvig et al. reported that $\mathrm{CD}_{133^{+}}$keratinocytes exhibit high mitochondrial potential that may have clinical implications in nonmelanoma skin cancer [20]. Roudi et al. have studied gene-expression profiling in $\mathrm{CD}_{133^{+}}$cells compared with $\mathrm{CD} 133^{-}$D10 cells. The data demonstrated that 130
Table 1 CSCs markers are used for their characterizations in melanoma

\begin{tabular}{|c|c|c|}
\hline Markers & Associated properties and functions & References \\
\hline CD133 & $\begin{array}{l}\text { - Tumor initiation } \\
\text { - Maintain long-term tumorigenic potential } \\
\text { - Chemoresistance } \\
\text { - Activates p38 MAPK pathway } \\
\text { - Induces metastasis and angiogenesis }\end{array}$ & {$[4,15]$} \\
\hline ABCG2 & - Tumor initiation & [4] \\
\hline CD271 & $\begin{array}{l}\text { - Associated with metastasis } \\
\text { - Establish tumor heterogeneity } \\
\text { - Maintain long-term tumor growth }\end{array}$ & [6] \\
\hline ABCB5 & $\begin{array}{l}\text { - Self-renewal and differentiation } \\
\text { - Tumor initiation } \\
\text { - Vasculogenic mimicry }\end{array}$ & {$[5,9]$} \\
\hline ALDH & $\begin{array}{l}\text { - Self-renewal and differentiation } \\
\text { - Highly tumorigenic } \\
\text { - Chemoresistance }\end{array}$ & [7] \\
\hline CD20 & $\begin{array}{l}\text { - Highly enrich in melanosphere } \\
\text { - Exhibit self-renewal }\end{array}$ & {$[3]$} \\
\hline PD-1 & $\begin{array}{l}\text { - Highly tumorigenic } \\
\text { • Help in the evasion of tumor immunity }\end{array}$ & [25] \\
\hline VEGFR1 & $\begin{array}{l}\text { - Higher tumor growth } \\
\text { - Vasculogenic mimicry } \\
\text { - Coexpressed with ABCB5 }\end{array}$ & [9] \\
\hline CXCR6 & $\begin{array}{l}\text { - Self-renewal } \\
\text { • Highly tumorigenic }\end{array}$ & [27] \\
\hline JARID1B & $\begin{array}{l}\text { - Give rise to highly proliferative progeny } \\
\text { - Self-renewal } \\
\text { - Exhibits continuous tumor growth and } \\
\text { metastasis } \\
\text { - Regulates Jagged1/Notch1 signaling }\end{array}$ & {$[30]$} \\
\hline
\end{tabular}

genes were upregulated including $\mathrm{ABC}$ transporter super-family (ABCC1, ABCG2 and ABCC6), while 61 genes were downregulated including apoptosis modifying genes (CASP8 and TNFRSF4). These data indicate that $\mathrm{CD} 133^{+} \mathrm{D} 10$ cells are highly resistant and aggressive in melanoma model [21]. More recently, Kumar et al. have shown that $\mathrm{CD}_{133^{+}}$melanoma specific CSCs maintain long term tumorigenic potential under in vivo condition [15]. Furthermore, stem cell associated markers, nestin and CD133 are highly expressed on circulatory melanoma cells which might represent an index of poor prognosis [22]. Other group has shown that receptor activator of NF- $\mathrm{KB}$ (RANK) expressing metastatic melanoma cells co-expressed ABCB5 and CD133 [23]. In accordance with previous reports, Schatton et al. have identified malignant melanoma-initiating cells (MMICs) which are capable of self renewal and differentiation and enriched on the basis of preferential expression of markers such as ABCB5 (a member of ATP-binding cassette) [5]. Moreover, it has also been reported that the amplification of ABCB5 is a predisposing factor for melanoma development which further emphasize the specific role of stem cells in melanoma growth [24]. In addition, $\mathrm{ABCB}^{+}$melanoma cells showed tumor 
initiation at the level of $1 \times 10^{5}$ cells, whereas 100 -fold more $\mathrm{ABCB}^{-}$cells are required to develop tumor under in vivo condition indicating the importance of CSCs in melanoma progression. In addition, $\mathrm{PD}-1^{+}$and $\mathrm{B} 7.2^{+}$cells in human melanoma are responsible for higher tumorigenicity compared with $\mathrm{PD}-1^{-}$and $\mathrm{B} 7.2^{-}$cells respectively. It has also been observed that the expression of PD-1 and B7.2 markers are coexpressed with ABCB5 [25]. Further, Fang et al. showed that $\mathrm{CD} 20^{+}$fraction from melanoma cells exhibit multipotent properties under in vitro and in vivo conditions [3]. The expression of VEGFR1 is highly upregulated and associated with tumor progression in malignant melanoma-initiating cells. In this study, the expression of VEGFR1 and its downstream signaling play a crucial role in $\mathrm{ABCB}^{+}$MMIC which govern the vasculogenic mimicry (VM) and higher tumor growth [9]. Moreover, Schlaak et al. have showed that elimination of $\mathrm{CD}^{+} 0^{+}$cells lead to regression of metastatic melanoma [26]. Furthermore, CXCR6 is a newly defined biomarker for identification and characterization of aggressive melanoma specific CSCs [27]. Civenni et al. have also characterized the CSCs based on expression of CD271, a specific melanoma stem cell marker [6]. In contrast, Boyle et al. have demonstrated that CD271 expression is unstable and not consistently linked to tumorigenicity in clinical melanoma patient's specimens [28]. Additionally, Li et al. have shown that the expression of CD271 is epigenetically regulated through DNA methylation. In this study, they have shown that expression of CD271 induced drastically when treated with 5-aza (an inhibitor of the methylase enzyme) for 6 days demonstrating that DNA methylation is involved in regulation of CD271 expression [29].

Roesch and their colleagues demonstrated that JAR$\mathrm{ID} \mathrm{B}^{+}$melanoma cells are slow-cycling that are responsible for giving rise to a highly proliferative progeny [30]. In addition, Kumar et al. have shown the existence of side population (SP) in melanoma which exhibits the properties of CSCs [10]. Recently, Luo et al. have well established the concept of CSCs in melanoma based on the intracellular stem cell marker ALDH where they have shown that $\mathrm{ALDH}^{+}$cells fulfil the criteria of selfrenewal and differentiation of CSCs upon serial transplantation into NOD/SCID mice. ALDH1A is a superfamily of detoxifying enzymes which metabolize a wide variety of intracellular aldehydes therefore providing chemoresistance in human melanoma stem cells, thus governing cancer cell proliferation and survival [7]. Recently, it has been observed that CD $44^{\text {high }} / A L D H 1 A 1^{\text {high }}$ cells were significantly higher in melanoma specimens which suggest a possible candidate for targeted therapy of skin cancer aiming to CSCs [31]. Dioxin receptor (AhR) integrates signaling pathways associated with xenobiotic metabolism and tissue or organ homeostasis. AhR is involved in dualistic role in tumor development.
However, AhR knockdown increased ALDH1A1 activity and enhances B16F10 melanoma growth through maintaining cancer stem-like phenotypes. Further, knockdown of ALDH1A1 reduced the levels of $\mathrm{CD} 133^{+} / \mathrm{CD} 29^{+} / \mathrm{CD} 44^{+}$ cells, melanosphere size and expression of Sox2, a pluripotency factor in AhR knockdown cells [32]. Taken together, these results demonstrate that existence of a subset of cells in melanoma with CSC-like features that can be identified based on specific unique markers.

The crosstalk between melanoma CSCs and angiogenesis Angiogenesis is an important hallmark of tumor development. Most of the genes that are upregulated in aggressive melanoma are known to be involved in angiogenesis and vasculogenesis, such as CD144, EPHA2 and LAMC2. These molecules are required for formation and maintenance of blood vessels. Some of these genes are also involved in vasculogenic mimicry leading to melanoma progression and metastasis [33]. Jin et al. have demonstrated the existence of EGFR-Akt-Smad signaling in stem like cells which promotes tumor angiogenesis by ID3 regulated cytokine induction [34]. Neovascularization in tumor is often associated with CSC-derived endothelial cells (ECs). Kumar et al. and Bussolati et al. have shown that renal and melanoma derived-CSCs are able to differentiate into endothelial like cells when cultured in endothelial cell growth specific medium $[15,35]$. Cumulative evidences have shown that CSCs are involved in the angiogenesis phenomenon. Monzani et al. have demonstrated that WM115 cells express angiogenic factors like VEGF, VEGFR-2, Ang1/2 and Tie2 along with melanoma specific CSCs signaling such as Notch4 [4]. Since melanoma specific CSCs have high degree of differentiation plasticity, they may contribute to the de novo formation of tumor blood vessels via a process termed vasculogenic mimicry (VM) [33]. In accord with these results, Frank et al. have demonstrated that $\mathrm{ABCB}^{+}$ human melanoma cells are specifically associated with vasculogenic mimicry by expressing endothelial specific and other angiogenic proteins. The same group has shown that human melanoma $\mathrm{ABCB}^{+}$subpopulation preferentially expresses the vasculogenic differentiation markers like Tie1 and CD144 (VE-cadherin) which are distinct from those expressed on mature $\mathrm{CD}^{+} 1^{+}$tumor endothelial cells [9]. $\mathrm{CD}_{133^{+}}$melanoma specific CSCs exhibit the functional tube formation and maintain the endothelial cell alignment through secretory factors present in their conditioned medium [15] as shown in Fig. 1. In addition, $\mathrm{ABCB}^{+}$and $\mathrm{CD}_{133^{+}}$melanoma specific CSCs preferentially express VEGFR1 and VEGF that are essential for VM in human melanoma cells $[9,15]$.

Lai et al. have identified that $\mathrm{CD}_{133^{+}}$and $\mathrm{ABCB}^{+}$subpopulations are colocalized in the perivascular niche of melanoma. This perivascular niche contains CD144 (VEcadherin $)^{+}$melanoma cells with vessel like channels. They 


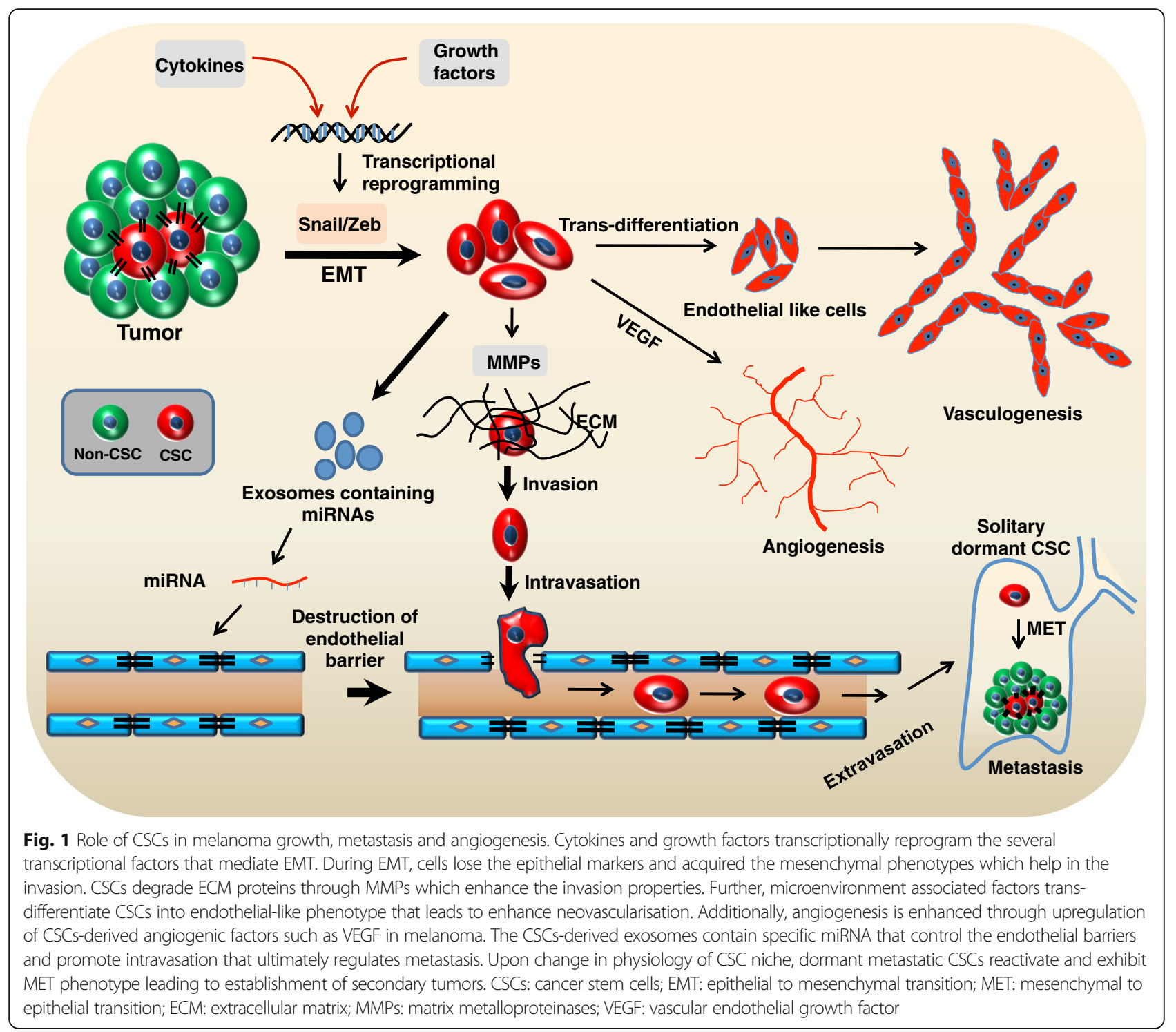

have further investigated the role of $\mathrm{CD}_{133^{+}}$cells in vasculogenic mimicry using $\mathrm{CD}_{133^{+}} / \mathrm{GFP}^{+}$melanoma cells under in vivo conditions. They have observed that vascular niches containing mosaic vessels that are partially lined up by both $\mathrm{CD} 144^{+} / \mathrm{GFP}^{+}$channels-forming melanoma cells and $\mathrm{CD}_{144^{+}} / \mathrm{GFP}^{-}$mouse endothelial cells [36]. Schnegg et al. have also demonstrated that perivascular niches exhibit higher accumulation of $\mathrm{CD} 133^{+}$and $\mathrm{CD} 271^{+}$melanoma stem cells [37]. It has been reported that CSCs from glioblastoma help in tumor vascularisation through recruitment of endothelial progenitor cells (EPCs) via VEGF and SDF1 [38]. Recently, it has been observed that melanoma cells educate mesenchymal stromal cells towards vasculogenic mimicry through various angiogenic factors [39]. Furthermore, a recent study shows that $\mathrm{CD} 133^{+}$D10 melanoma cells exhibit a significant induction of early angiogenesis under in vivo condition compared with CD133- D10 cells [40]. Interestingly, VM-forming melanoma cells are positive for CD271 [41] and the data supports that VEGFR1 and PKC $\alpha$ signaling control melanoma VM [42].

Moreover, Harell et al. have showed that primary melanoma induces sentinel lymph node lymphangiogenesis prior to initiation of dissemination [43]. Subsequent study demonstrated that VEGF-A in cutaneous squamous cell carcinoma and VEGF-C in melanoma induces the sentinel lymph node lymphangiogenesis and promotes lymphatic metastasis $[44,45]$. However, the detailed mechanism of melanoma specific CSCs in lymphangiogenesis need to be investigated further. All these observations clearly emphasized the role of melanoma specific CSCs in angiogenesis and lymphangiogenesis leading to melanoma growth. 


\section{Melanoma CSCs in metastasis and tumor recurrence}

Metastasis is the intermediate phenomenon of the tumor development. Tumor metastasis is established by several phenotypic changes and processes such as invasive growth, escape from primary site, intravasation, lymphatic and haematogenous survival, extravasation and colonization at distant organs. During metastasis, tumor cells lose or gain several adhesion molecules such as ALCAM, VE-cadherin, L1-CAM, integrin $\beta 3$, ICAM-1, E-cadherin and Ncadherin [46]. Malignant melanoma is a highly metastatic disease having survival period of less than 5 years. It mostly metastasizes to lungs and also affects other visceral organs. Several clinical reports suggest that regional lymph node metastasis is a determinant of outcome for patients with melanoma. The presence of regional lymph node metastasis is commonly used as an indication for systemic and adjuvant therapy. However, the potential risk of recurrence greatly varies in each individual due to heterogeneous nature of the tumors [47].

Al Dhaybi et al. and Rappa et al. have shown the existence of CD $133^{+}$CSCs in development of malignant melanoma and their potential to metastasize in lymph nodes, lung and/or other visceral organs. These cells expressed low level of proliferative maker Ki-67 that may associate with the chemoresistant ability of CSCs $[48,49]$. Fusi et al. have observed the co-expression of CD133 with Nestin on circulatory melanoma cells. These data highlighted that the patient survival rate is low with Nestin overexpressed circulatory melanoma cells compared to low Nestin expressed cells [22]. Additionally, Klein et al. observed significant increase in the expression of stem cell markers, CD133, CD166 and Nestin in primary and metastatic melanoma cells [50]. Furthermore, it has been shown that $\mathrm{CD}_{20} 0^{+} \mathrm{CSCs}$ are responsible for metastasis [26]. Moreover, Civenni et al. and de Waard et al. have also established the link between metastasis and $\mathrm{CD}_{2} 71^{+}$or $\mathrm{ABCB}^{+}$melanoma stem cells $[6,51]$. In addition, Kumar et al. have shown that side population in melanoma cells have higher metastatic capacity as compared with those of non-side population [10]. Several reports suggest that ALDH1 is a potential marker in CSCs derived from melanoma. Genetic ablation of ALDH1A1 by its specific shRNA resulted not only significant reduction in tumor growth but also exhibited significant decrease in metastatic burden in melanoma [52]. Furthermore, clinical data strongly suggests that RANK is highly upregulated on melanomainitiating cells and the expression of RANK is higher in metastases as compared to primary tumor [23]. Zhao et al. have recently showed that $\mathrm{CD} 133^{+} \mathrm{CD} 44^{+}$melanoma CSCs are highly metastatic towards lung [53]. During invasion, tumor cells exhibit different phenotypic changes through epigenetic modifications. Studies revealed that combined expression of EZH2, H3K4me2 and
H3K27me3 might correlate with potential CSCs properties. Moreover, the expressions of EZH2, H3K4me2 and H3K27me3 were enhanced significantly at the invasive site of tumor. However, expressions of these molecules were less in metastatic sites as compared to patients with primary melanoma cases [54].

Additionally, recent clinical data showed that there were significant increase in the number of $\mathrm{ABCB} 5^{+} \mathrm{CD} 271$ ${ }^{+} \mathrm{RANK}^{+}$CSCs in circulatory tumor cells (CTCs) at late stage of melanoma. These data indicate that CTCs are highly enriched in CSCs which are responsible for establishment of distant secondary tumors [55]. Ojha et al. have reported that autophagy in CSCs establish a potential link between chemoresistance, metastasis and recurrence in several tumors [56]. Several lines of evidences suggest that some of the metastasized tumor solitary cells exist in a quiescent like state accompanied by decreased expression of proliferation specific markers. The tumor dormancy might caused by several mechanisms such as stress induced by microenvironment, programming of the transcriptional factors and therapeutic treatment of the primary tumor [57]. Additional data also suggest that CSCs are predominantly quiescent in nature and that may contribute to dormancy [58]. Changes in microenvironment including proproliferative, pro-inflammatory and pro-angiogenic molecules may lead to the mobilization and activation of dormant CSCs [57]. Stereotactic body radiation therapy promotes recurrence of melanoma through mesenchymal stem cells (MSCs) recruitment and pericytes differentiation leading to vasculogenesis [59]. The exosomes enhance the metastatic behaviour of primary tumors by educating bone marrow progenitors through MET (a receptor tyrosine kinase) from highly metastatic melanoma [60]. Gao et al. have demonstrated the mediator and suppressor molecules for metastatic reactivation in breast cancer cells by using forward genetic screening approach in mice [61]. The immune-surveillance may induces dormancy in single cutaneous malignant melanoma cells by blocking their proliferation cycle [62]. All these results suggest that CSCs are involved in the formation of metastatic lesion and tumor recurrence (Fig. 1).

\section{Melanoma CSCs and EMT}

In the process of metastasis, cells need to disseminate from their primary site where tumor cells lose the epithelial phenotype and gain the mesenchymal status termed as epithelial-to-mesenchymal transition (EMT). Upon reaching to secondary site, these reprogrammed cells exhibit a reversal process designated as mesenchymal-to-epithelial transition (MET) as shown in Fig 1. Mounting evidences have demonstrated that EMT induced by different factors, is associated with tumor aggressiveness and metastasis and these cells share molecular characteristic with CSCs [63]. EMT is driven by several transcription factors (TF) 
such as Snail, Slug, Twist and Zeb and studies showed that EMT-inducer control the progression of malignant melanoma $[63,64]$. Recent studies also showed that silencing of CD133 downregulates Slug and Snail expression [15]. Yao et al. have shown that epithelial splicing regulatory protein 1 (ESRP1) is associated with EMT in addition to Slug, Snail and Zeb in human malignant melanoma. It has been shown that the expressions of epithelial markers were higher in tumors with full-length ESRP1. In contrast, the expression of mesenchymal markers is higher in tumors with low level of ESRP1 [65]. Recent studies have highlighted that EMT-inducer has antagonistic function in melanoma progression. In melanocytes, the expressions of Snail2 and Zeb2 were found to be higher and act as oncosuppressor whereas Twist1 and Zeb1 promote neoplastic transformation of melanocytes and aberrantly reactivate in melanoma [66]. Other studies have shown that Slug regulates Zeb1 expression in melanoma at transcriptional level through binding to the E-boxes of promoter [64]. Guo et al. have showed that BRAF activates long non-coding RNA (BANCR) that induces EMT phenomenon and contribute to cancer cell migration [67].

Several lines of evidences suggest that EMT plays a crucial role in tumor metastasis and recurrence which is tightly linked with the CSCs biology. Accumulative data indicate that $\mathrm{CD} 133^{+}$cells exhibit EMT phenotype and maintained stemness properties $[68,69]$. In addition, CD133 facilitates EMT through interaction with ERK pathway [68]. The study also revealed that S100A4, a master mediator for EMT maintains tumor-initiating cells (TICs) [70]. Several reports indicate that EMT promotes CSCs phenotype [70, 71]. Mani et al. have demonstrated that overexpression of Twist and Snail enhances EMT in immortalized human mammary epithelial cells that resulted in acquisition of $\mathrm{CD} 44^{\text {high }} / \mathrm{CD} 24^{\text {low }}$ expression and higher mammosphere-forming ability [72]. Zeb1 expression is closely associated with maintenance of CD133 ${ }^{+} \mathrm{CD} 44^{+}$CSCs-like properties in B16F10 cells that include colony formation, drug resistance, migration and invasion. Knockdown of Zeb1 leads to inhibition of tumorigenicity and metastasis in $\mathrm{CD} 133^{+} \mathrm{CD} 44^{+}$B16F10 specific CSCs. In addition, downregulation of Zeb1 reverse the EMT phenotype of $\mathrm{CD} 133^{+} \mathrm{CD} 44^{+}$CSCs. These data suggested that Zeb1 maintained the CSCs properties and EMT phenotype in melanoma cells [73]. Downregulation of Zeb1, Twist1 and Snail1 attenuates the invasive properties of uveal melanoma cells [74]. GLI transcription factor is identified as the effectors of the Hedgehog signaling pathway. Apart from Zeb, Snail and Twist that regulate Ecadherin and GLI-2 forms a complex with Zeb1 and exhibits the repression of E-cadherin in human melanoma cells [75]. It is well documented that microphthalmiaassociated transcription factor (MITF) determine the cell fate of melanocyte. In addition, Zeb2 is needed for proper differentiation of melanocyte through regulation of MITFZEB1 transcription network. Knocking down of Zeb2 leads to significant downregulation of MITF and concomitant upregulation of Zeb1, Vimentin and Fibronectin resulted in enhanced melanoma progression [76]. Recent study also supports that insulin-like growth factor binding protein 5 (IGFBP5) acts as a tumor suppressor in human melanoma by inhibiting EMT phenotype and attenuates the expression of stem cell markers such as Nanog, Sox2, Oct4, KLF4 and CD133 [77]. In contrast, immune-related GTPase family protein IRGMI induces B16 melanoma cell migration, invasion and EMT through F-actin polymerization [78]. In addition to EMT, the mesenchymal to amoeboid transition (MAT), a second type of motility shift is essential for melanoma tumor progression. The programming of MAT exhibits increased in stem-like and colonogenic features of melanoma cells. Overexpression of EphA2 or RacN17 in melanoma cells induces MAT like phenotype which leads to increase in tumor invasion [79].

Several solid tumors including melanoma exhibit extracellular acidosis. Peppicelli et al. showed that exposing melanoma cells with an acidic extracellular environment $(\mathrm{pH}$ 6.7) upregulate the expression of mesenchymal markers such as $\mathrm{N}$-cadherin, Vimentin whereas the expression of epithelial specific marker such as E-cadherin was found to be downregulated. Further, these data also suggest that acidic environment enhanced the melanoma cell invasion and lung colonization through upregulation of MMP-9 activity [80]. Apart from several cytokine and growth factor, TGF $\beta$ acts as key player to induce EMT in several cancers including breast and melanoma [72, 81]. In addition, TGF $\beta$ also promotes amoeboid feature that leads to higher melanoma migration and dissemination [82]. Overall, these reports indicate that CSC is linked with EMT features in association with several microenvironmental factors (Fig. 1).

\section{Role of CSCs in regulation of immune cells in melanoma} Compelling evidences suggest that tumors are immunogenic in nature and melanoma is one of the well characterized model [83]. Melanoma cells display multiple antigens and peptide epitopes that help the host immune system to respond either serologically or through cellmediated mechanisms [83]. However, the question remained unsolved why tumors cannot be eliminated by the immune system. CSCs are responsible for recurrence of tumors and are associated with immune escape mechanism [13]. Therefore, to prevent the contribution of CSCs in tumor growth, several groups have studied whether the effector immune cytotoxic cells like NK cells, CD8 $\mathrm{T}$ cells and $\gamma \delta \mathrm{T}$ cells could eliminate the CSCs compartments [84]. 
Recently, it has been shown that anti-apoptotic proteins such as $\mathrm{Bcl} 2, \mathrm{Bcl}-\mathrm{xl}$ or survivin not only protect CSCs against chemotherapeutic agents, but also enhance resistance for apoptosis-inducing immune effectors like NK- or T- cells [13]. The data revealed that due to low level of expression of MHC class I molecule, these CSCs are poorly recognized by T lymphocytes. However, CSCs can be eliminated by $\gamma \delta \mathrm{T}$ lymphocytes upon sensitization with bisphosphonate zoledronate [85]. Recent data demonstrate that CSCs derived from colon cancer, glioblastoma as well as melanoma can be recognized by NK cells [84]. In contrast, Pietra et al. have shown that melanoma cells impair the function of NK cells through inhibiting the expression of major receptors including NKp30, NKp44 and NKG2D which are associated with cytolytic activity. Further, they have observed that this inhibitory effect was primarily mediated by indoleamine 2,3-dioxygenase (IDO) and prostaglandin E2 (PGE2) [86]. Moreover, overexpression of $6 \mathrm{kDa}$ early secreted antigenic target (ESAT-6), a glycosylphosphatidylinositol (GPI)-anchored form and secreted interleukin (IL)-21 in B16F10 CD $133^{+} \mathrm{CD} 44^{+} \mathrm{CSCs}$ leads to activation of anti-ESAT- 6 and interferon (IFN)- $\gamma$ correlates with enhanced anti-melanoma efficacy and prolonged survival of melanoma bearing mice [53]. It has been shown that IL-2 and IL-15 activate NK cells and exhibit enhanced cytotoxicity against CSCs derived from melanoma and breast cancer $[87,88]$. Moreover, NK cells preferentially eliminate $\mathrm{CD} 24^{+} / \mathrm{CD} 44^{+}, \mathrm{CD}_{133^{+}}$and $\mathrm{ALDH}{ }^{\text {bright }} \mathrm{CSCs}$ in variety of human cancer cell lines through upregulation of NKG2D ligands [89]. Schattan et al. have shown that $\mathrm{ABCB}^{+}$malignant melanoma initiating cells exhibit lower expression of melanoma associated antigens such as MART-1, ML-IAP, NY-ESO-1 and MAGE-A which might help them in escaping from immune surveillance mechanism. Furthermore, $\mathrm{ABCB} 5^{+}$melanoma cells inhibit T-cell activation through $\mathrm{IL}-2$ and induce $\mathrm{CD} 4^{+} \mathrm{CD} 25^{+} \mathrm{FoxP}^{+}$ regulatory $\mathrm{T}$ (Treg) cells via $\mathrm{B} 7.2$ dependent manner [25]. However, CD271 ${ }^{+}$melanoma cells does not express TYR, MART1 and MAGE antigens which propel them for immune resistance against T cells [90]. Moreover, overexpression of CD271 in melanoma cells suppressed melanomaspecific cytotoxic $\mathrm{T}$ lymphocytes (CTLs) under in vitro conditions. Additionally, CTLs-derived IFN- $\gamma$ induces CD271 expression in melanoma cells that is associated with downregulation of production of melanoma antigens [91]. These data demonstrate a novel mechanism for evasion of anti-tumor immunity. In contrast, $\mathrm{CD} 133^{+}$melanoma CSCs express high level of cancer/testis (CT) antigens which make them more susceptible against $\mathrm{CD}^{+} \mathrm{T}$ lymphocytes [92]. Recently, a new study showed that CD133 ${ }^{+}$ murine melanoma cells express DDX3X antigen which is immunogenic and able to protect melanoma growth in Tcell dependent manner [93]. Further, IL-6 induces melanoma differentiation whereas IL-10 supports the enrichment of undifferentiated melanoma stem like compartment [94]. Immune system also regulates the EMT process which is consistent with earlier findings. Kudo-Suito et al. showed that Snail-induced EMT accelerates cancer metastasis through invasion and induction of immunosuppression by CD4 ${ }^{+}$Foxp $3^{+}$Treg cells [95].

\section{Signaling mechanism in melanoma specific CSCs}

In past, significant progress has been made towards understanding the molecular mechanism of malignant melanoma. Several reports suggest that CSCs are responsible for limited tumor response against conventional treatment due to specific intracellular molecular properties [14]. Thus, delineating the signaling pathways by which CSCs control tumor-protective mechanisms will provide the better understanding of tumor relapse.

Signaling mechanism has been extensively studied in embryonic stem cells for their maintenance or selfrenewal and these are common in CSCs. Khalkhali-Ellis et al. demonstrated that Nodal which maintain pluripotency of embryonic stem cells and plasticity of melanoma CSCs, interact with heterodimeric receptors of Activin I and II in embryonic stem cells whereas it binds with TGF $\beta R 1$ and II in metastatic melanoma [96]. Alcohol consumption causes the risk associated with several human cancers. Recent study showed that ethanol exposure to FEMX-I melanoma cells increase the percentage of $\mathrm{CD}_{27}{ }^{+}$CSCs. Ethanol activates NF-kB by decreasing its p50 homodimers which leads to enhancement of CD271 expression [97]. Melanoma specific CSCs are involved in establishment of metastases that is determined by several signaling cascades. Sonic hedgehog (Shh), Wnt or Notch regulatory signaling pathways modulate the differentiation plasticity and promote selfrenewal of stem cells [98]. Several reports have shown the presence of these signaling pathways and their therapeutic targets in various types of stem cells. Geng et al. have shown that Hedgehog $(\mathrm{HH})$ pathway play a vital role in development of melanogenesis in murine melanoma models [99]. Moreover, abolishment of HH-GLI signaling pathway drastically attenuates the self-renewal and tumor initiating potential of $\mathrm{ALDH}^{\text {bright }}$ melanoma CSCs [100]. In addition, Pandolfi et al. have shown that effectors of $\mathrm{HH}$ signaling, GLI1/2 regulates transcription factor E2F1 which is essential for cell proliferation and tumor progression in melanoma. Further, E2F1 modulates iASPP (inhibitor of apoptosis-stimulating protein of p53) by directly binding to the promoter region of iASPP and enhance the proliferation indicating that $\mathrm{HH}$ GLI-E2F1-iASPP axis is essential for melanoma progression [101]. Moreover, Wnt signaling has been implicated in regulation of self-renewal and proliferation of normal stem and cancer cells [98]. High level of Wnt receptor, FZD7 is associated with enhanced metastatic potential 
of melanoma cells. Knocking down of FZD7 suppressed JNK activation and metastatic growth in melanoma [102]. Similarly, Notch signaling plays a critical role in regulating cell to cell communication during embryogenesis, cellular proliferation, differentiation and apoptosis [103]. Notch receptors cleaved by $\gamma$-secretase and TACE (Tumor Necrosis Factor- $\alpha$-Converting Enzyme) resulted in release of NICD (Notch Intracellular Domain) that translocate into nucleus and regulate the promoter activity of various genes. Attenuation of $\gamma$ secretase and TACE leads to downregulation of NICD2 and Hes1 which preferentially inhibit melanosphere formation indicating that Notch2 regulates melanoma progression in CSCs [104]. It has been also shown that Notch4 promotes invasion and metastasis in melanoma stem-like cells [105]. Additionally, Akt regulates nucleocytoplasmic shuttling of NICD4 [106]. In addition, activated Notch1 increases the stability of $\beta$-catenin that play important role in melanoma cell migration and proliferation [107]. Recent data showed that Notch1 signaling is highly augmented in $\mathrm{CD}_{133^{+}} \mathrm{CSCs}$ in melanoma. NICD1 binds to the promoter region of CD133 and transcriptionally regulates its expression. Further, Notch1-CD133 signaling axis activates p38-MAPK pathway that leads to AP-1-DNA binding and regulates the expression of MMPs and VEGF that are essential for metastasis and angiogenesis [15]. Moreover, recent study showed that tetraspanin, TM4SF promotes CSCs phenotype in breast cancer cells. Mechanistically, collagen I but not IV, fibronectin and laminin 1 induces TM4SFmediated coupling of DDR1 to PKC $\alpha$ and augment JAK2-STAT3 signaling which is essential for reactivation of the dormant solitary tumor cells for establishment of multi-organ site metastatic out growth [108].

The comparative analysis of monolayer vs 3D spheroid showed that neural progenitor genes that includes ID4 (Inhibitor of DNA Binding 4) switched from 3Dspheroid to highly differentiated morphology indicating that ID4 plays a crucial role in the maintenance of CSCs phenotype in melanoma cells [109]. In contrast, IGFBP5 acts as tumor suppressor in melanoma through attenuation of stem-like cell activity (Fig. 2). IGFBP5 disrupt the binding of IGF to IGFR1 leading to inactivation of ERK1/2 and p38 MAPK pathway that preferentially attenuates HIF1 $\alpha$ regulated VEGF and MMPs gene expression [77]. Interestingly, TGF $\beta$ markedly induces EMT phenotype in several cancers including breast and melanoma. Schlegel et al. have demonstrated that PI3K and PDGF signaling are important for TGF $\beta$-induced EMT in human melanoma cells. TGF $\beta$ activates SMAD signaling which in turn regulates PDGF and its receptor expression leading to activation of PI3K-Akt pathway which contributes EMT in melanoma [81]. TGF $\beta$ also induces the amoeboid migration of melanoma cells which is alternative of EMT. Downstream of TGF $\beta$, SMAD2 and its adaptor CITED1 regulate the amoeboidal characteristic of melanoma cells. Moreover, TGF $\beta$ SMAD2-CITED1 signaling axis induces melanoma cell attachment to endothelial cells, lung colonization and metastatic out growth [82]. Rh123 ${ }^{\text {low }}$ (Low Rhodamine 123) cells exhibit stem-like phenotype correlate with enhanced levels of HIF $1 \alpha$, Oct 4 and ABCB5 and reduced level of Cyclin D1 and CDK4 which define the quiescent and chemoresistance properties of CSCs in melanoma. It has been also reported that PI3K/Akt pathway is involved in the maintenance of $\mathrm{Rh} 123^{\text {low }}$ in melanoma stem cell compartment [110]. Attenuation of PI3K/Akt downregulates TNF-mediated enrichment of GFP ${ }^{\text {high }}$ label-retaining in CSCs in melanoma [111]. Vasculogenic mimicry (VM) plays a crucial role in melanoma angiogenesis. VEGF-A is a well known regulator of tumor vascularisation. Inhibition of VEGFR2 kinase activity with PTKi-II (protein tyrosine kinase inhibitor II) does not affect VM in melanoma cells however, attenuation of VEGFR1 significantly disrupts this process. In addition, inhibition of PKC $\alpha$ abrogates vasculogenic mimicry. Taken together, these data suggest that VEGFR1 and PKC $\alpha$ signaling regulates VM in melanoma [42]. In addition, deficiency of p63, a p53 homolog suppresses tumor growth. Interestingly, the isoform of p63, $\Delta \mathrm{Np} 63 \alpha$ bypasses the senescence to promote stem-like cell proliferation and tumorigenesis in skin cancer under in vivo condition [112]. Moreover, $\Delta \mathrm{Np} 63 \alpha$ enhances the expression and activation of Akt1 and p-Akt1 which preferentially induces the proliferation and survival of cancer cell [113]. Overall, all these data suggest that molecular signaling plays an important role in CSCsmediated melanoma progression (Fig. 2).

\section{CSCs and microenvironment in melanoma}

Like normal stem cells, CSCs are regulated by cell to cell communications with their non-tumorigenic cancer population or stromal cells to sustain their own interdiscipline [114]. Tumor progression also depends on several secreted factors or other niche component, site of injection and species-species host milieu. Rao et al. have demonstrated that tumor associated macrophage (TAM) interacts with CSCs and secrete osteopontin (OPN) which enhances the tumorigenicity and clonogenicity in colorectal cancer [115]. These CSCs might also reciprocally regulate surrounding niche through the secretion of specific growth factor that regulates OPN expression in TAM. Moreover, Kale et al. have shown that macrophage in association with melanoma enhances the OPN expression that further regulates Cox 2 production and controls melanoma growth and angiogenesis [116]. Kumar et al. have also demonstrated that stromal OPN enriches SP-phenotype which ultimately control 


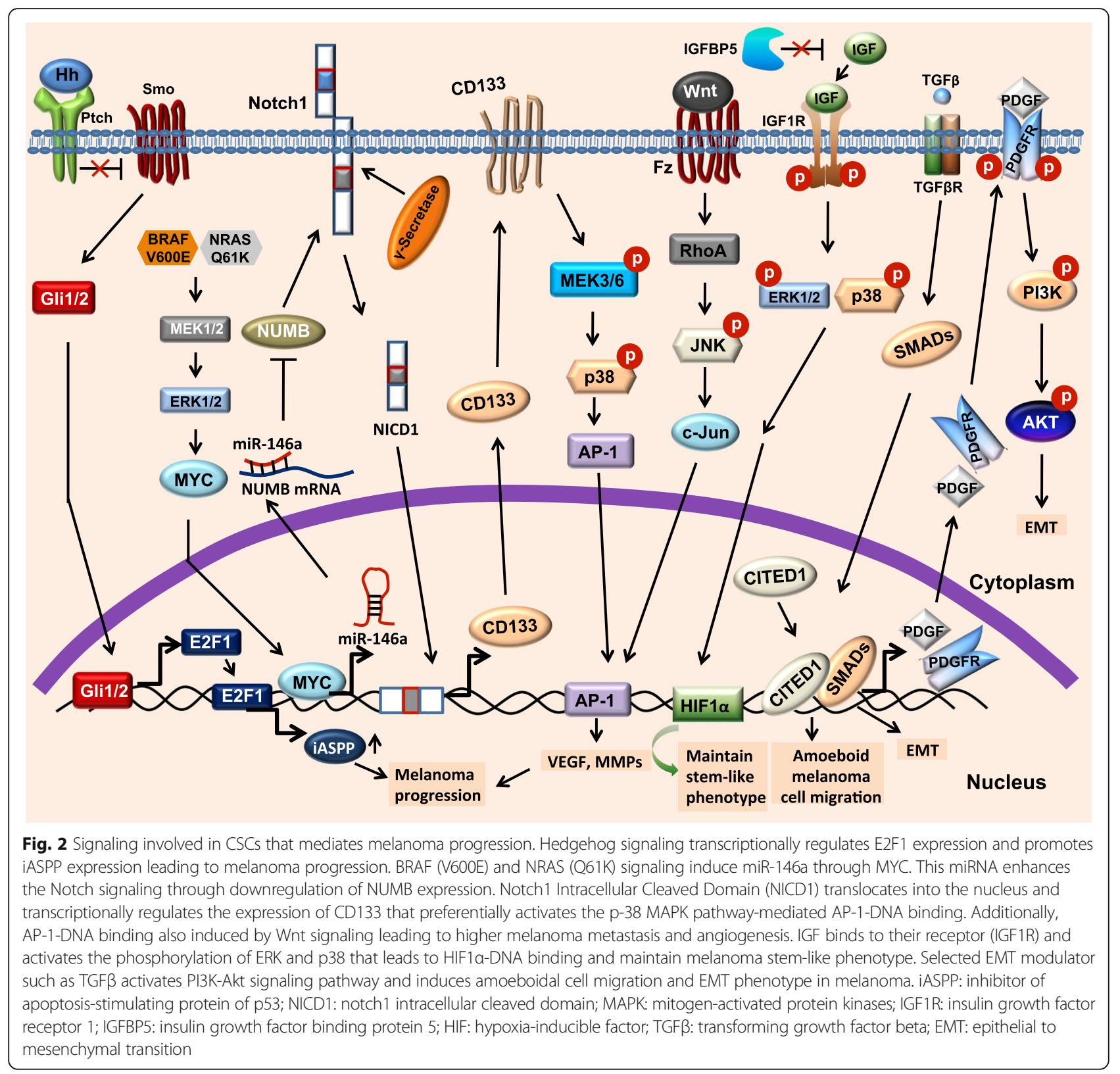

melanoma progression [10]. Hypoxic microenvironment plays an important role in tumor progression and controls tumor stem cell population by stabilizing hypoxia inducible factor (HIF) [117]. HIF1 and HIF2 are the subfamily of hypoxia inducible transcription factors which are activated in tumor hypoxic regions and are responsible to initiate a complex set of cellular response in tumor cells. It has been reported that HIF1 $\alpha$ and HIF2 $\alpha$ are involved in invasion and invadopodia formation and associated with melanoma metastases in patients. HIF1 $\alpha$ increases VEGF expression and decreases E-cadherin levels that are crucial for angiogenesis and metastasis $[118,119]$. Furthermore, hypoxic microenvironment enriches the higher expression of CD133 and VEGFR2 as compared with normoxic conditions that lead to enhanced melanoma growth [120]. Additionally, MFG-E8 induces VEGF and ET-1 expression in MSCs and enhances M2 macrophage polarization that leads to higher angiogenesis and melanoma growth under hypoxic conditions [121]. Taken together, these studies established the role of tumor microenvironment in CSCs-mediated melanoma progression.

\section{Function of miRNA in melanoma specific CSCs}

Several reports have suggested that miRNAs may act as early diagnostic and prognostic biomarker in many cancers including melanoma [122]. Initially, miRNAs that suppress or promote metastasis have been identified in 
breast cancer [123, 124]. Subsequent studies have revealed that many miRNAs regulate tumor growth, angiogenesis and metastasis in various other cancers. Additionally, the expression of miRNA strongly correlates with various steps of melanoma progression (Fig. 1 and 2). Therefore, deregulation in miRNA expression and function appears to be a pervasive feature of human cancers (Table 2).

Several studies have shown that cluster of miRNA such as miR-1908, miR-199a-3p and miR-199a-5p drive metastatic invasion, endothelial recruitment and angiogenesis. Further, these miRNA cooperatively attenuates ApoE and DNAJA4 which are required for suppression of cell invasion and endothelial recruitment by engaging LRP1 and LRP8 that ultimately associates with metastatic progression [125]. miRNA profiling revealed that miR-125a-5p suppresses melanoma growth through down regulation of TGF $\beta$ signaling by direct targeting Lin28B, a well known inhibitor of Let-7 miRNA biogenesis. Further, clinical data indicated that Lin28B was aberrantly expressed in large number of melanoma patients [126]. A direct plasma assay has been developed to detect circulating miRNA-210 as indicator which can be used for early metastatic recurrence in melanoma under hypoxic environment [122]. In depth studies also revealed that there are differential expression patterns of miRs which correlate CSCs and EMT phenotypes. These data suggest that metastasis and EMT associated miR10b, miR-21, miR-200c, miR-373 and miR-520c are highly upregulated in melanosphere as compared with monolayer [16]. Tumor derived exosomes also contain miRNAs including miR-105 which help in destroying the vascular endothelial barrier [17].

Noman et al. have shown that hypoxia-inducible miR210 regulates the susceptibility of tumor cells against cytotoxic T cells [127]. They have shown that hypoxia predominantly induces miR-210 expression in melanoma cells through HIF1 $\alpha$-dependent manner. Further, miR-210 confers resistant in hypoxic tumor cells against cytotoxic $\mathrm{T}$ cell-mediated lysis through targeting PTPN1, HOXA1 and
TP53I11 genes. The results speculate that this miRNA must have role in immune suppression in hypoxic regions of melanoma where CSCs and metastatic phenotypes are known to evolve [127]. In contrast, other groups have shown that hypoxia induces downregulation of miR-340-5p expression which is responsible for upregulation of melanoma-stem cell associated marker, ABCB5 [128]. Additionally, overexpression of miR-200c in $\mathrm{CD} 44^{+} \mathrm{CD} 133^{+}$ CSCs resulted in downregulation of Zeb1 expression, reduction in cell proliferation, colony formation, cell migration and invasion as well as tumorigenic potential in melanoma [129]. Moreover, miR-33b suppresses EMT and migratory potential of melanoma cell by direct binding to 3'-UTR of HMGA2 and suppresses its expression [130]. miRNA also help in the communication between cancer cell and their microenvironment. The co-culture of melanoma cells with astrocytes downregulates miR-768-3p expression in melanoma cells which confer the chemoresistance and CSCs properties [131]. Moreover, several other miRNAs also act as mediator and communicators with tumor-associated macrophage (TAM), cancer-associated fibroblast (CAF), cancer-associated endothelial cell (CAEC) and cancer-associated mesothelial cell (CAMC) [132]. Most of the melanoma develops due to BRAF and NRAS mutation. miR-146a is regulated by BRAF and NRAS genes as shown by small RNA profiling. Further, BRAF-MEK-ERK signaling enhances the expression of miR-146a through transcriptional regulation and protein stability. Overexpression of miR-146a increases human melanoma cell proliferation and promotes tumor initiation by targeting NUMB mRNA, a repressor of Notch signaling. A single nucleotide $\mathrm{C}$ to $\mathrm{G}$ somatic mutation in miR-146a causes enhanced Notch signaling and promotes oncogenesis [133]. Oncogenic DNp73, a dominant-negative variant of tumorsuppressor p73 confers enhanced stem-like properties in melanoma through attenuation of miR-885-5p which regulates IGF1R that is responsible for expression of stemness marker [134]. Augmentation of miR-9 significantly decreases melanoma cell proliferation and migration. This miRNA attenuates the expression of Snail1 with

Table 2 miRNAs associated with CSCs in melanoma

\begin{tabular}{|c|c|c|}
\hline miRNA & Functions & References \\
\hline miR-10b, miR-21, miR-200c, miR-373 and miR-520c & Regulate EMT & [16] \\
\hline miR-340-5p & Controls ABCB5 expression & [128] \\
\hline miR-200c & Regulates Zeb1 expression, cell proliferation and invasion & [129] \\
\hline miR-33b & Suppresses EMT and cell migration & [130] \\
\hline miR-885-5p & Maintains stemness feature and controls proliferation and metastasis & [134] \\
\hline miR-9 & Decreases proliferation and metastasis & [135] \\
\hline miR-155 & Regulates NK cell activity & [158] \\
\hline miR-34a & Target Notch1 signaling pathway & [159] \\
\hline miR-222 & Controls Wnt and PI3K-Akt pathways and regulates CSCs phenotype & [160] \\
\hline
\end{tabular}


concomitant increase in E-cadherin expression. Mechanistically, miR-9 binds to 3'-UTR of NF- $\mathrm{kB}$ and attenuates their expression which preferentially inhibits Snail 1 that ultimately leads to inhibition of melanoma cell proliferation and metastasis [135].

\section{Therapeutic implications of melanoma specific CSCs}

Cancer stem cells rarely divide and have distinct cellular physiology from the remaining bulk of tumor population. Traditional chemotherapy and radiation therapy are not sufficient to eradicate these CSCs from patients with cancer. Since CSCs have high level of transporter that pump out chemotherapeutic agents which make CSCs more chemoresistant. CSCs are also radio-resistant because of preferential activation of DNA damage checkpoint and DNA repair capacity [136]. In order to control melanoma growth, it is necessary to target melanoma stem cells because it governs the recurrence of tumors and metastasis after many years and may act as reservoir of therapeutically resistant cells.

Melanoma specific CSCs carry specific marker (CD133, CD20, ABCB5, CD271 and ALDH1) or antigens, so targeting these cells using monoclonal antibodies could help to combat melanoma growth. Rappa et al. have demonstrated that downregulation of CD133 in human metastatic melanoma cells (FEMX-1) attenuates the melanosphere formation and metastatic potential. Further, monoclonal antibodies against different epitopes of CD133 showed dose-dependent cytotoxic effect [49]. Since melanoma specific CSCs express CD20, therefore rituximab therapy is used in clinical trials to treat metastatic melanoma patients by targeting $\mathrm{CD} 20^{+}$cells. The CD20 antibody therapy depletes CD20 positive melanoma cells and eliminates peripheral $B$ cells that elevates in malignant melanoma patients [26]. Vincristine (VCR) is commonly used for melanoma therapy however it is ineffective against melanoma specific CSCs. Song et al. investigated that VCR-containing immuno-liposome conjugated with CD20 antibody (VCRLip-CD20) is 1.85 fold more effective than VCR alone in melanoma. They have further demonstrated that VCR-LipCD20 selectively eliminates $\mathrm{CD} 20^{+}$melanoma cells and attenuates tumorigenic ability of WM266-4 melanosphere under in vivo condition [137]. Etoposide alone is not able to eliminate $\mathrm{CD} 133^{+}$melanoma specific CSCs that express high level of VEGFR2. However, combination of Etoposide with Bevacizumab significantly induces apoptosis and abolishes sphere-forming ability of $\mathrm{CD} 133^{+}$CSCs in melanoma [120]. Schatton et al. have also demonstrated that there was selective elimination of ABCB5 population in melanoma using a monoclonal antibody against $\mathrm{ABCB} 5$ under in vivo mice model [5]. Recently, $\mathrm{ABCB}^{+}$cells in melanoma have shown to suppress $\mathrm{T}$ cell activation and thus have specific role for immune evasion [5]. Therefore, targeting the immune system in melanoma patient with IL-2 and IFN- $\alpha$ could be important therapeutic approach [138]. Similarly, Biasco et al. and Flaherty et al. have shown that Temozolomide and Dacarbazine (DTIC) could be important therapeutic agents for treatment of metastatic melanoma [139, 140]. Since CSCs are also maintained by specific signaling cascade therefore targeting these cells using DAPT (Notch inhibitor), Cyclopamine (Hh signaling inhibitor), XAV939 (Wnt signaling inhibitor), or DTIC could be appropriate strategies for treatment of melanoma patient [141-143]. In addition, Demcizumab (anti-Notch ligand, DLL4 antibody), OMP-52M51 (anti-Notch1 antibody), OMP-18R5 (antiWnt receptor, FZD monoclonal antibody) and BBI608 (inhibitor of Stat 3 and $\beta$-catenin pathways) could be better therapeutic agents to combat melanoma [144] (Fig. 3). Recent studies have shown that Andrographolide (Andro), derived from Andrographis paniculata, attenuates tumor growth through abrogation of Notch1-mediated CD133dependent p38 MAPK activation pathway in $\mathrm{CD} 133^{+}$melanoma cells. In addition, Andro also impairs the EMT, angiogenesis and metastasis properties of these $\mathrm{CD} 133^{+}$ cells. Similar to DTIC, Dabrafenib or Trametinib those commonly used for treatment of melanoma, Andro also targets $\mathrm{CD}_{133^{+}} \mathrm{CSCs}$ and suppressed melanoma growth and lung metastasis [15]. These data indicated that Andro may act as a potential anti-cancer agent for the eradication of CSCs-dependent melanoma progression.

Recent advancements in targeting Bcl2 family members are an alternative option to combat melanoma and overcome relapse or resistance of melanoma. To prevent this relapse, it is necessary to develop effective therapies that eradicate all subpopulation of tumor cells including resistant CSCs subpopulation in melanoma. Bcl2 family members play a crucial role in cancer resistance mechanism and contributes to chemoresistant ability of CSCs and their survival $[145,146]$. Several Bcl2 proteins are downstream of commonly activated RAS/BRAF/MAPK and PI3K/Akt signaling pathways which play an important role in tumor initiation and maintenance of melanoma specific CSCs compartment [146]. Small molecule inhibitor such as $\mathrm{BH} 3$ mimetic which mimics the proapoptotic BH3 protein and induces apoptosis is currently a successful approach. Additionally, ABT-263 is a mimetic of BAD that inhibits anti-apoptotic proteins such as Bcl2, Bcl-xl and Bcl-w $[145,146]$. Another, small molecule ABT-737 that inhibits Bcl2, Bcl-xl or Bcl-w is a promising agent for treatment of cancers. Moreover, synthetic retinoid fenretinide $\mathrm{N}$-(4-hydroxyphenyl) retinamide (4-HPR) is another promising agent for the management of breast cancer. Interestingly, the data shown that combination of ABT-737 and 4-HPR significantly eliminate $\mathrm{ALDH}^{+} \mathrm{CSCs}$ in multiple melanoma cell lines including BRAF and NRAS mutant cells [145]. Further, combination of anti-apoptotic MCL-1 protein inhibitor, SC-2001 and ABT-737 significantly depletes 


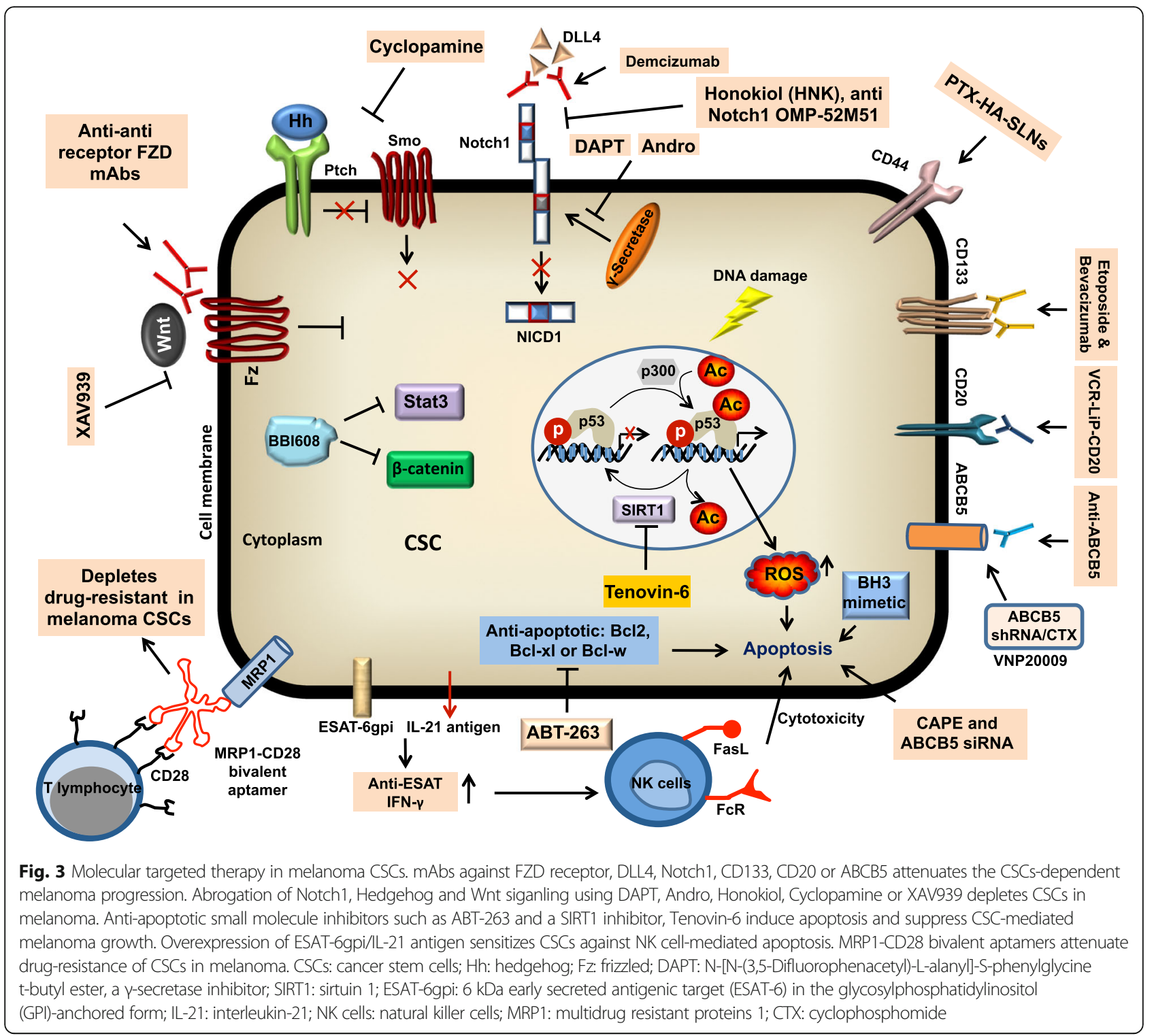

$\mathrm{ALDH}^{+}$cells in melanoma [147]. Most of the CSCs exhibit chemoresistance through attribution of enhanced drug efflux mediated by ATP-binding cassette sub family $B$ (ABCB). The results revealed that caffeic acid phenethyl ester (CAPE), a bioactive molecule induces apoptosis in ABCB5 knocked down $\mathrm{CD} 133^{+}$chemoresistant melanoma cells. CAPE activates E2F1 gene which trigger apoptosis through mitochondrial dysfunction, ER stress and induction of pro-apoptotic genes such as Bax, Noxa and Puma. These observations suggest that combination of ABCB5 siRNA and CAPE can de-bulk the tumor mass and eliminate chemoresistance in melanoma specific CSCs [148]. Recent study also demonstrates that inhibition of deacytylase activity of Sirtuin 1 and 2 (SIRT1/ 2) by Tenovin-6 induces apoptosis in uveal melanoma by upregulating the expression of tumor suppressor gene, p53 and elevation of ROS. Tenovin- 6 eliminates the $\mathrm{ALDH}^{+} \mathrm{CSCs}$ compartments and inhibits the growth and migration of uveal melanoma [149].

Despite recent advances in immunotherapy for cancer, the efficacy of this strategy remains limited. Several studies have indicated that CSCs are weak in immunogenicity due to low expression of antigens which is one of the prime obstacles for induction of anti-tumor immune response. Overexpression of ESAT-6-gpi and IL-21 antigens in $\mathrm{CD}_{133}{ }^{+} \mathrm{CD} 44^{+}$melanoma specific CSCs enhanced the levels of anti-ESAT- 6 and interferon (IFN)- $\gamma$ as well as increased cytotoxic activities of NK cells, splenocytes and complement dependent cytotoxicity leading to attenuation of melanoma growth and metastases [53] (Fig. 3). Moreover, ALDH ${ }^{\text {high }}$ melanoma CSCs lyastepulsed dendritic cells (DCs) act as a better vaccine which 
leads to significant reduction in tumor growth and lung metastases. Further, administration of ALDH ${ }^{\text {high }}$ CSCsDC vaccine significantly attenuates $A L D H^{\text {high }}$ CSCs percentage in primary tumors through specific binding of IgG produced by primed B cell resulting in lysis of target cells in the presence of complement [150]. Recent study revealed a novel bi-specific aptamer which have two CD28 motifs and able to costimulate $\mathrm{T}$ lymphocytes and promotes tumor immunity. Other MRP1 motif that is capable to bind MRP1 aptatope of chemoresistant CSCs. The in vivo results revealed that systemic administration of MRP1-CD28 bi-valent aptamer exhibits higher concentration in $\mathrm{B} 16-\mathrm{MRP}^{\text {high }}$ tumor as compared with B16 parental tumors which leads to downregulation of B16-MRP ${ }^{\text {high }}$ tumor growth efficiently [151].

Several studies have indicated that CD44 is a CSC marker in various cancers including melanoma. It binds specially to hyaluronic acid. Shen et al. have demonstrated that coating solid lipid nanoparticles with hyaluronan (HA-SLNs) allowed targeted delivery of Paclitaxel (PTX) to CD44 ${ }^{+}$B16F10 melanoma cells. PTX loaded HA-SLNs significantly abrogate tumor growth and lung metastasis [152]. Additionally, combined treatment with engineered VNP20009, carrying shABCB5 and Cyclophosphomide (CTX) drastically reduced $\mathrm{ABCB} 5^{+} \mathrm{CSCs}$ that leads to attenuation of melanoma tumor growth and enhanced survival time [153]. Blocking HedgehogGLI signaling with smoothened (SMO) and GLI antagonist by Cyclopamine and Gant61 remarkably attenuates tumor initiating properties of $\mathrm{ALDH}^{\text {high }}$ melanoma stem cells [100]. Moreover, Honokiol (HNK), a biphenolic natural compound reduces the expression of various stem cell markers such as CD271, CD166, JARID1B and ABCB5 in melanoma. Furthermore, HNK also significantly attenuates CSC properties through inhibition of Notch signaling [104]. Therefore, understanding the signaling cross-talk, tumor microenvironment and identification of novel targets in CSCs may allow us for more effective combinatorial antitumor therapies (Fig. 3).

\section{Limitation, barriers and controversy in melanoma specific CSCs}

It has long been recognized that tumors are heterogeneous in nature that is being confirmed with several functional and phenotypic properties to validate the existence of CSCs in many cancer including melanoma. After several decades, debates still continues whether melanoma contain CSCs and the origin of melanoma CSCs. The identification and characterization of CSCs may help in the elimination of CSCs in melanoma. However, CSCs have several limitations such as they exihibit normal stem cell like self-renewal property, DNA repair mechanism, oxidative state and resistance to xenobiotic toxins. Therefore, targeting CSCs in tumor might also affect normal stem cells and hence distinct molecular features of CSCs need to be established for the management of CSC-mediated therapy in melanoma [154].

Several lines of evidences indicate that CSCs present in the melanoma which in turn responsible for diseases progression [3-6]. In contrast, Quintana et al. have extensively demonstrated that phenotypic heterogeneity among tumorigenic melanoma cells is reversible and not hierarchically organized [155]. Additionally, other study showed that only rare human melanoma cells (0.1$0.0001 \%$ ) are able to induce tumor upon transplantation into NOD/SCID mice model. However, using a highly immunocompromised NOD/SCID interleukin-2 receptor gamma chain null ( $\left.\mathrm{Il} 2 \mathrm{rg}^{-/-}\right)$mice model demonstrate that approximately $25 \%$ of unselected melanoma cells formed tumor [156]. These results indicate that melanoma does not follow CSCs model and the percentage of tumorigenic cells is common that depends on tumor microenvironment. Moreover, Boiko et al. have showed that CD271 ${ }^{+}$ melanoma cells exhibit CSCs properties that depend on immunocompromised mouse strain, site of injection and cell suspension preparation [90]. These observation suggested that the tumorigenic potential of CSCs also depends on the arrival of the fresh tissue from surgical theatre, process of obtaining a single cells suspension to derive highest number of viable cells, exclusion of dead cells and debris, flow cytometry sorting of CSCs with high yield and purity and transplantation time into recipient model after sorting. The intrinsic tumorigenic potential of human melanoma CSCs also defined by microenvironment in immunocompromised mice model. Therefore, it is critical to assess the relevance of CSCs hypothesis in melanoma using appropriate model system [157]. In addition, we have recently demonstrated that melanoma are heterogeneous in nature. $\mathrm{CD}_{133^{+}} \mathrm{CSC}$ s derived from melanoma cells exhibit long term tumorigenic potential in isograft mice model which partly exclude the possibility of the artificial milieu [15]. These data demonstrate that functional studies are required to identify and characterize CSCs population. Additional studies are needed in order to understand the pathophysiological function of CSCs in tumor progression.

\section{Conclusions and future directions}

Malignant melanoma is a deadly disease with historically poor prognosis. Due to presence of heterogeneous subpopulation and existence of CSCs, it is difficult to completely cure such a devastating disease. The continued attempt for the identification of CSCs in melanoma and other cancers led to promise the field of CSCs research in order to understand the management of cancers. CSCs exhibit extensive contribution in tumor growth, angiogenesis and reactivation in metastatic out growth through several 
genetic and epigenetic changes, EMT or stromal microenvironmental factors. CSCs are also responsible for therapeutic resistant that led to tumor relapse. Specific signaling mechanisms are required for the maintenance of CSCs in tumor that can maintain their microenvironment. Therefore, CSCs are becoming priority targets for the development of novel antitumor therapy.

The tumor milieu is a critical regulator of melanoma specific CSCs-driven angiogenesis and metastasis. Signaling effectors from ECM or stromal cells can act as EMT or MET inducer or may regulate dormancy at metastatic sites in CSCs. Furthermore, defined cellular programmes allow CSCs to modify their milieu through the autocrine/ paracrine signals that increases invasiveness, metastasis and angiogenesis. These programmes also promote CSCs features and associate with the determination of the CSCs fate. Several reports suggest that CSCs are more chemoresistant which show higher expression of drug efflux pump and inhibitor of pro-apoptotic molecules. CSCs are weak in immunogenic nature due to lack of expression of sufficient antigens. Overexpression of specific antigens lead to eradicate melanoma specific CSCs and attenuates tumor progression. Several microRNAs such as miR-200c and miR-33b act as suppressor through targeting specific signaling cascade. It is known that miRNAs can interact with many important regulatory pathways during CSCdependent melanoma progression such as MAPK/ERK and PI3K/Akt. Therefore, identification of potential therapeutic agents that may regulate these specific miRNAs which will allow to eradicate the root cause of melanoma development, angiogenesis and metastasis. Considering the unique biology of CSCs, there is great need to develop novel and promising approaches for CSCs targeted cancer therapy. Several studies indicate that controversy of melanoma CSCs arises due to inappropriate mice model and lack of proper functional assays. Considering the controversy, limitation and barriers targeting CSCs, future direction of research are needed to establish or identify the distinct features of CSCs with compared to normal stem cells. In this review, we have discussed that there are several small molecule inhibitors (HNK, ABT-737, ABT-263), nanoparticles conjugated drugs (HA-SLNs-PTX), signaling antagonist (Cyclopamine, Gant61), monoclonal receptor antibodies (anti-CD20, anti-CD133, anti-ABCB5) and microRNAs (miR-200c, miR-33b) those could be used as novel therapeutic strategies for management of melanoma. In addition, recent data showed that Andrographolide may act as a potent anti-cancer agent by targeting Notch1 pathway in CSCs that ultimately suppresses malignant melanoma growth (Fig. 3). Moreover, additional studies are required to target root cause of melanoma growth and metastasis using personalized and combination therapy.

\section{Abbreviations}

CSC: Cancer stem cells; DAPT: N-[N-(3,5-Difluorophenacetyl)-L-alanyl]-Sphenylglycine t-butyl ester, a $y$-secretase inhibitor; ECM: Extracellular matrix; EMT: Epithelial to mesenchymal transition; ESAT-6gpi: 6 kDa early secreted antigenic target (ESAT-6) in the glycosylphosphatidylinositol (GPI)-anchored form; Fz: Frizzled; Hh: Hedgehog; HIF: Hypoxia-inducible factor;

IASPP: Inhibitor of apoptosis-stimulating protein of p53; IGF1R: Insulin growth factor receptor 1; IGFBP5: Insulin growth factor binding protein 5; IL-

21: Interleukin-21; MAPK: Mitogen-activated protein kinases;

MET: Mesenchymal to epithelial transition; MMPs: Matrix metalloproteinases; MRP1: Multidrug resistant proteins 1; NICD1: Notch1 intracellular cleaved domain; NK cells: Natural killer cells; SIRT1: Sirtuin 1; TGF $\beta$ : Transforming growth factor beta; VEGF: Vascular endothelial growth factor

\section{Acknowledgments}

We thank Ms. Anuradha Bulbule and Ms. NNV Radharani for critically reading this article and constructive suggestions for this review. We apologize to many colleagues whose contributions could not site due to lack of space.

\section{Funding}

None.

Availability of data and materials

Yes.

\section{Authors' contribution}

DK performed literature search, designed and draft the manuscript, prepare the figures and tables. MG and GK participated in the literature search, managed the references, wrote some sections and critically revised the manuscript. GCK designed the article, participate in the writing and analysis of the information and approved the version to be published. All authors read and approved the final manuscript.

\section{Competing interests}

The authors declare no competing interests.

\section{Consent for publication}

N/A.

\section{Ethics approval and consent to participate}

$\mathrm{N} / \mathrm{A}$.

\section{Author details}

'Laboratory of Tumor Biology, Angiogenesis and Nanomedicine Research, National Centre for Cell Science (NCCS), Pune411007India. ${ }^{2}$ Deapartment of Biology, Northeastern University, Boston, MA02115USA.

Received: 12 October 2016 Accepted: 25 December 2016

Published online: 30 January 2017

\section{References}

1. Bonnet D, Dick JE. Human acute myeloid leukemia is organized as a hierarchy that originates from a primitive hematopoietic cell. Nat Med. 1997;3(7):730-7.

2. Chin L, Garraway LA, Fisher DE. Malignant melanoma: genetics and therapeutics in the genomic era. Genes Dev. 2006;20(16):2149-82.

3. Fang D, Nguyen TK, Leishear K, Finko R, Kulp AN, Hotz $S$, et al. A tumorigenic subpopulation with stem cell properties in melanomas. Cancer Res. 2005;65(20):9328-37.

4. Monzani E, Facchetti F, Galmozzi E, Corsini E, Benetti A, Cavazzin C, et al. Melanoma contains CD133 and ABCG2 positive cells with enhanced tumourigenic potential. Eur J Cancer. 2007;43(5):935-46.

5. Schatton T, Murphy GF, Frank NY, Yamaura K, Waaga-Gasser AM, Gasser M, et al. Identification of cells initiating human melanomas. Nature. 2008; 451(7176):345-9.

6. Civenni G, Walter A, Kobert N, Mihic-Probst D, Zipser M, Belloni B, et al. Human CD271-positive melanoma stem cells associated with metastasis establish tumor heterogeneity and long-term growth. Cancer Res. 2011; 71(8):3098-109. 
7. Luo Y, Dallaglio K, Chen Y, Robinson WA, Robinson SE, McCarter MD, et al. ALDH1A isozymes are markers of human melanoma stem cells and potential therapeutic targets. Stem Cells. 2012;30(10):2100-13.

8. Biddle A, Liang X, Gammon L, Fazil B, Harper LJ, Emich H, et al. Cancer stem cells in squamous cell carcinoma switch between two distinct phenotypes that are preferentially migratory or proliferative. Cancer Res. 2011;71(15): 5317-26.

9. Frank NY, Schatton T, Kim S, Zhan Q, Wilson BJ, Ma J, et al. VEGFR-1 expressed by malignant melanoma-initiating cells is required for tumor growth. Cancer Res. 2011;71(4):1474-85.

10. Kumar S, Sharma P, Kumar D, Chakraborty G, Gorain M, Kundu GC Functional characterization of stromal osteopontin in melanoma progression and metastasis. PLoS One. 2013;8(7):e69116.

11. Li Z, Bao S, Wu Q, Wang H, Eyler C, Sathornsumetee S, et al. Hypoxiainducible factors regulate tumorigenic capacity of glioma stem cells. Cancer Cell. 2009;15(6):501-13.

12. Liu S, Kumar SM, Martin JS, Yang R, Xu X. Snail1 mediates hypoxia-induced melanoma progression. Am J Pathol. 2011;179(6):3020-31.

13. Bruttel VS, Wischhusen J. Cancer stem cell immunology: key to understanding tumorigenesis and tumor immune escape? Front Immunol. 2014:5:360.

14. Skvortsov S, Debbage P, Lukas P, Skvortsova I. Crosstalk between DNA repair and cancer stem cell (CSC) associated intracellular pathways. Semin Cancer Biol. 2015;31:36-42.

15. Kumar D, Kumar S, Gorain M, Tomar D, Patil HS, Radharani NN, et al. Notch1MAPK signaling axis regulates $\mathrm{CD} 133^{+}$cancer stem cell-mediated melanoma growth and angiogenesis. J Invest Dermatol. 2016;136(12):2462-74.

16. Fomeshi MR, Ebrahimi M, Mowla SJ, Khosravani P, Firouzi J, Khayatzadeh H. Evaluation of the expressions pattern of miR-10b, 21, 200c, 373 and 520c to find the correlation between epithelial-to-mesenchymal transition and melanoma stem cell potential in isolated cancer stem cells. Cell Mol Bio Lett. 2015;20(3):448-65.

17. Zhou W, Fong MY, Min Y, Somlo G, Liu L, Palomares MR, et al. Cancersecreted miR-105 destroys vascular endothelial barriers to promote metastasis. Cancer Cell. 2014;25(4):501-15.

18. Fabbri M, Paone A, Calore F, Galli R, Gaudio E, Santhanam R, et al. MicroRNAs bind to Toll-like receptors to induce prometastatic inflammatory response. Proc Natl Acad Sci U S A. 2012:109(31):E2110-6.

19. Lobo NA, Shimono Y, Qian D, Clarke MF. The biology of cancer stem cells. Annu Rev Cell Dev Biol. 2007;23:675-99.

20. Nordvig AS, Owens DM, Morris RJ. CD133 in the selection of epidermal stem cells in mice: steps in the right direction. J Invest Dermatol. 2012; 132(11):2492-4.

21. Roudi R, Ebrahimi M, Sabet MN, Najafi A, Nourani MR, Fomeshi MR, et al. Comparative gene-expression profiling of CD133+ and CD133-D10 melanoma cells. Future Oncol. 2015;1 1(17):2383-93.

22. Fusi A, Reichelt U, Busse A, Ochsenreither S, Rietz A, Maisel M, et al. Expression of the stem cell markers nestin and CD133 on circulating melanoma cells. J Invest Dermatol. 2011:131(2):487-94.

23. Kupas V, Weishaupt C, Siepmann D, Kaserer ML, Eickelmann M, Metze D, et al. RANK is expressed in metastatic melanoma and highly upregulated on melanoma-initiating cells. J Invest Dermatol. 2011;131(4):944-55.

24. Bertolotto C, Lesueur F, Giuliano S, Strub T, de Lichy M, Bille K, et al. A SUMOylation-defective MITF germline mutation predisposes to melanoma and renal carcinoma. Nature. 2011:480(7375):94-8.

25. Schatton T, Schütte U, Frank NY, Zhan Q, Hoerning A, Robles SC, et al. Modulation of T-cell activation by malignant melanoma initiating cells. Cancer Res. 2010;70(2):697-708.

26. Schlaak M, Schmidt P, Bangard C, Kurschat P, Mauch C, Abken H. Regression of metastatic melanoma in a patient by antibody targeting cancer stem cells. Oncotarget. 2012;3(1):22-30.

27. Taghizadeh R, Noh M, Huh YH, Ciusani E, Sigalotti L, Maio M, et al. CXCR6, a newly defined biomarker of tissue-specific stem cell asymmetric selfrenewal, identifies more aggressive human melanoma cancer stem cells. PLoS One. 2010;5(12):e15183.

28. Boyle SE, Fedele CG, Corbin V, Wybacz E, Szeto P, Lewin J, et al. CD271 expression on patient melanoma cells is unstable and unlinked to tumorigenicity. Cancer Res. 2016;76(13):3965-77.

29. Li S, Yue $D$, Chen $X$, Wang L, Li J, Ping Y, et al. Epigenetic regulation of CD271, a potential cancer stem cell marker associated with chemoresistance and metastatic capacity. Oncol Rep. 2015;33(1):425-32.
30. Roesch A, Fukunaga-Kalabis M, Schmidt EC, Zabierowski SE, Brafford PA, Vultur A, et al. A temporarily distinct subpopulation of slow-cycling melanoma cells is required for continuous tumor growth. Cell. 2010;141(4):583-94.

31. Erfani E, Roudi R, Rakhshan A, Sabet MN, Shariftabrizi A, Madjd Z. Comparative expression analysis of putative cancer stem cell markers CD44 and ALDH1A1 in various skin cancer subtypes. Int J Biol Markers. 2016;31(1):e53-61.

32. Contador-Troca M, Alvarez-Barrientos A, Merino JM, Morales-Hernández A, Rodríguez Ml, Rey-Barroso J, et al. Dioxin receptor regulates aldehyde dehydrogenase to block melanoma tumorigenesis and metastasis. Mol Cancer. 2015;14:148.

33. Hendrix MJC, Seftor EA, Hess AR, Seftor RE. Vasculogenic mimicry and tumourcell plasticity: lessons from melanoma. Nat Rev Cancer. 2003;3(6):411-21.

34. Jin X, Yin J, Kim SH, Sohn YW, Beck S, Lim YC, et al. EGFR-AKT-Smad signaling promotes formation of glioma stem-like cells and tumor angiogenesis by ID3-driven cytokine induction. Cancer Res. 2011;71(22): 7125-34.

35. Bussolati B, Bruno S, Grange C, Ferrando U, Camussi G. Identification of a tumor-initiating stem cell population in human renal carcinomas. FASEB J. 2008;22(10):3696-705.

36. Lai CY, Schwartz BE, Hsu MY. CD133+ melanoma subpopulations contribute to perivascular niche morphogenesis and tumorigenicity through vasculogenic mimicry. Cancer Res. 2012;72(19):5111-8.

37. Schnegg Cl, Yang MH, Ghosh SK, Hsu MY. Induction of vasculogenic mimicry overrides VEGF-A silencing and enriches stem-like cancer cells in melanoma. Cancer Res. 2015;75(8):1682-90.

38. Folkins C, Shaked Y, Man S, Tang T, Lee CR, Zhu Z, et al. Glioma tumor stem-like cells promote tumor angiogenesis and vasculogenesis via vascular endothelial growth factor and stromal-derived factor 1. Cancer Res. 2009; 69(18):7243-51.

39. Vartanian A, Karshieva S, Dombrovsky V, Belyavsky A. Melanoma educates mesenchymal stromal cells towards vasculogenic mimicry. Oncol Lett. 2016; 11(6):4264-8.

40. Zimmerer RM, Matthiesen P, Kreher F, Kampmann A, Spalthoff S, Jehn P, et al. Putative CD133+ melanoma cancer stem cells induce initial angiogenesis in vivo. Microvasc Res. 2016:104:46-54.

41. Valyi-Nagy K, Kormos B, Ali M, Shukla D, Valyi-Nagy T. Stem cell marker CD271 is expressed by vasculogenic mimicry-forming uveal melanoma cells in three-dimensional cultures. Mol Vis. 2012;18:588-92.

42. Vartanian A, Stepanova E, Grigorieva I, Solomko E, Baryshnikov A, Lichinitser $M$. VEGFR1 and PKCa signaling control melanoma vasculogenic mimicry in a VEGFR2 kinase-independent manner. Melanoma Res. 2011;21(2):91-8.

43. Harrell MI, ritani BM, Ruddell A. Tumor-induced sentinel lymph node lymphangiogenesis and increased lymph flow precede melanoma metastasis. Am J Pathol. 2007;170(2):774-86.

44. Hirakawa S, Kodama S, Kunstfeld R, Kajiya K, Brown LF, Detmar M. VEGF-A induces tumor and sentinel lymph node lymphangiogenesis and promotes lymphatic metastasis. J Exp Med. 2005;201(7):1089-99.

45. Rinderknecht $\mathrm{M}$, Detmar $\mathrm{M}$. Tumor lymphangiogenesis and melanoma metastasis. J Cell Physiol. 2008;216(2):347-54.

46. Swart GW, Lunter PC, Kilsdonk JW, Kempen LC. Activated leukocyte cell adhesion molecule (ALCAM/CD166): signaling at the divide of melanoma cell clustering and cell migration? Cancer Metastasis Rev. 2005;24(2):223-36.

47. White RR, Stanley WE, Johnson JL, Tyler DS, Seigler HF. Long-term survival in 2,505 patients with melanoma with regional lymph node metastasis. Ann Surg. 2002;235(6):879-87.

48. Al Dhaybi R, Sartelet H, Powell J, Kokta V. Expression of CD133 ${ }^{+}$cancer stem cells in childhood malignant melanoma and its correlation with metastasis. Mod Pathol. 2010;23(3):376-80.

49. Rappa G, Fodstad O, Lorico A. The stem cell-associated antigen CD133 (Prominin-1) is a molecular therapeutic target for metastatic melanoma. Stem Cells. 2008;26(12):3008-17.

50. Klein WM, Wu BP, Zhao S, Wu H, Klein-Szanto AJ, Tahan SR. Increased expression of stem cell markers in malignant melanoma. Mod Pathol. 2007; 20(1):102-7

51. de Waard NE, Kolovou PE, McGuire SP, Cao J, Frank NY, Frank MH, et al. Expression of multidrug resistance transporter $\mathrm{ABCB} 5$ in a murine model of human conjunctival melanoma. Ocul Oncol Pathol. 2015;1(3):182-9.

52. Yue L, Huang ZM, Fong S, Leong S, Jakowatz JG, Charruyer-Reinwald A, et al. Targeting ALDH1 to decrease tumorigenicity, growth and metastasis of human melanoma. Melanoma Res. 2015;25(2):138-48. 
53. Zhao F, He X, Sun J, Wu D, Pan M, Li M, et al. Cancer stem cell vaccine expressing ESAT-6-gpi and IL-21 inhibits melanoma growth and metastases. Am J Transl Res. 2015;7(10):1870-82.

54. Kampilafkos P, Melachrinou M, Kefalopoulou Z, Lakoumentas J, Sotiropoulou-Bonikou G. Epigenetic modifications in cutaneous malignant melanoma: $\mathrm{EZH} 2, \mathrm{H} 3 \mathrm{~K} 4 \mathrm{me} 2$, and H3K27me3 immunohistochemical expression is enhanced at the invasion front of the tumor. Am J Dermatopathol. 2015;37(2):138-44.

55. Gray ES, Reid AL, Bowyer S, Calapre L, Siew K, Pearce R, et al. Circulating melanoma cell subpopulations: their heterogeneity and differential responses to treatment. J Invest Dermatol. 2015;135(8):2040-8.

56. Ojha R, Bhattacharyya S, Singh SK. Autophagy in cancer stem cells: a potential link between chemoresistance, recurrence, and metastasis. Biores Open Access. 2015;4(1):97-108.

57. Osisami M, Keller ET. Mechanisms of metastatic tumor dormancy. J Clin Med. 2013;2(3):136-50

58. Kusumbe AP, Bapat SA. Cancer stem cells and aneuploid populations within developing tumors are the major determinants of tumor dormancy. Cancer Res. 2009;69(24):9245-53

59. Wang HH, Cui YL, Zaorsky NG, Lan J, Deng L, Zeng XL, et al. Mesenchymal stem cells generate pericytes to promote tumor recurrence via vasculogenesis after stereotactic body radiation therapy. Cancer Lett. 2016; 375(2):349-59.

60. Peinado H, Alečković M, Lavotshkin S, Matei I, Costa-Silva B, Moreno-Bueno $\mathrm{G}$, et al. Melanoma exosomes educate bone marrow progenitor cells toward a pro-metastatic phenotype through MET. Nat Med. 2012;18(6):88391.

61. Gao H, Chakraborty G, Lee-Lim AP, Mavrakis KJ, Wendel HG, Giancotti FG. Forward genetic screens in mice uncover mediators and suppressors of metastatic reactivation. Proc Natl Acad Sci U S A. 2014;111(46):16532-7.

62. Piérard-Franchimont C, Hermanns-Lê T, Delvenne P, Piérard GE. Dormancy of growth-stunted malignant melanoma: sustainable and smoldering patterns. Oncol Rev. 2014;8(2):252

63. Caramel J, Papadogeorgakis E, Hill L, Browne GJ, Richard G, Wierinckx A, et al. A switch in the expression of embryonic EMT-inducers drives the development of malignant melanoma. Cancer Cell. 2013;24(4):466-80.

64. Wels $\mathrm{C}$, Joshi $\mathrm{S}$, Koefinger $\mathrm{P}$, Bergler $\mathrm{H}$, Schaider $\mathrm{H}$. Transcriptional activation of ZEB1 by Slug leads to cooperative regulation of the epithelialmesenchymal transition-like phenotype in melanoma. J Invest Dermatol. 2011;131(9):1877-85.

65. Yao J, Caballero OL, Huang Y, Lin C, Rimoldi D, Behren A, et al. Altered expression and splicing of ESRP1 in malignant melanoma correlates with epithelial-mesenchymal status and tumor-associated immune cytolytic activity. Cancer Immunol Res. 2016;4(6):552-61.

66. Richard G, Puisieux A, Caramel J. Antagonistic functions of EMT-inducers in melanoma development: implications for cancer cell plasticity. Cancer Cell Microenviron. 2014;1(1):e61.

67. Guo Q, Zhao Y, Chen J, Hu J, Wang S, Zhang D, et al. BRAF-activated long non-coding RNA contributes to colorectal cancer migration by inducing epithelial-mesenchymal transition. Oncol Lett. 2014;8(2):869-75.

68. Ding Q, Miyazaki Y, Tsukasa K, Matsubara S, Yoshimitsu M, Takao S. CD133 facilitates epithelial-mesenchymal transition through interaction with the ERK pathway in pancreatic cancer metastasis. Mol Cancer. 2014;13:15.

69. Moon Y, Kim D, Sohn H, Lim W. Effect of CD133 overexpression on the epithelial-to-mesenchymal transition in oral cancer cell lines. Clin Exp Metastasis. 2016;33(5):487-96.

70. Lo JF, Yu CC, Chiou SH, Huang CY, Jan Cl, Lin SC, et al. The epithelialmesenchymal transition mediator S100A4 maintains cancer-initiating cells in head and neck cancers. Cancer Res. 2011;71(5):1912-23.

71. Morel AP, Lièvre M, Thomas $C$, Hinkal G, Ansieau S, Puisieux A. Generation of breast cancer stem cells through epithelial-mesenchymal transition. PLoS One. 2008;3(8):e2888.

72. Mani SA, Guo W, Liao MJ, Eaton EN, Ayyanan A, Zhou AY, et al. The epithelial-mesenchymal transition generates cells with properties of stem cells. Cell. 2008;133(4):704-15

73. Zhao F, He X, Wang Y, Shi F, Wu D, Pan M, et al. Decrease of ZEB expression inhibits the B16F10 cancer stem-like properties. Biosci Trends. 2015;9(5):325-34

74. Asnaghi L, Gezgin G, Tripathy A, Handa JT, Merbs SL, van der Velden PA, et al. EMT-associated factors promote invasive properties of uveal melanoma cells. Mol Vis. 2015;21:919-29.
75. Perrot CY, Gilbert C, Marsaud V, Postigo A, Javelaud D, Mauviel A. GLI2 cooperates with ZEB1 for transcriptional repression of $\mathrm{CDH} 1$ expression in human melanoma cells. Pigment Cell Melanoma Res. 2013;26(6):861-73.

76. Denecker G, Vandamme N, Akay O, Koludrovic D, Taminau J, Lemeire K, et al. Identification of a ZEB2-MITF-ZEB1 transcriptional network that controls melanogenesis and melanoma progression. Cell Death Differ. 2014;21(8):1250-61.

77. Wang J, Ding N, Li Y, Cheng H, Wang D, Yang Q, et al. Insulin-like growth factor binding protein 5 (IGFBP5) functions as a tumor suppressor in human melanoma cells. Oncotarget. 2015;6(24):20636-49.

78. Tian L, Li L, Xing W, Li R, Pei C, Dong X, et al. IRGM1 enhances B16 melanoma cell metastasis through PI3K-Rac1 mediated epithelial mesenchymal transition. Sci Rep. 2015;5:12357.

79. Taddei ML, Giannoni E, Morandi A, Ippolito A, Ramazzotti M, Callari M, et al. Mesenchymal to amoeboid transition is associated with stem-like features of melanoma cells. Cell Commun Signal. 2014;12:24.

80. Peppicelli S, Bianchini F, Torre E, Calorini L. Contribution of acidic melanoma cells undergoing epithelial-to-mesenchymal transition to aggressiveness of non-acidic melanoma cells. Clin Exp Metastasis. 2014;31(4):423-33.

81. Schlegel NC, von Planta A, Widmer DS, Dummer R, Christofori G. PI3K signalling is required for a TGF $\beta$-induced epithelial-mesenchymal-like transition (EMT-like) in human melanoma cells. Exp Dermatol. 2015;24(1):22-8.

82. Cantelli G, Orgaz JL, Rodriguez-Hernandez I, Karagiannis P, Maiques O, Matias-Guiu X, et al. TGF- $\beta$-induced transcription sustains amoeboid melanoma migration and dissemination. Curr Biol. 2015;25(22):2899-914.

83. Mukherji B. Immunology of melanoma. Clin Dermatol. 2013;31(2):156-65.

84. Tallerico R, Garofalo C, Carbone E. A new biological feature of natural killer cells: the recognition of solid tumor-derived cancer stem cells. Front Immunol. 2016;7:179.

85. Todaro M, D'Asaro M, Caccamo N, lovino F, Francipane MG, Meraviglia S, et al. Efficient killing of human colon cancer stem cells by $\gamma \delta$ T lymphocytes. J Immunol. 2009;182(11):7287-96.

86. Pietra G, Manzini C, Rivara S, Vitale M, Cantoni C, Petretto A, et al. Melanoma cells inhibit natural killer cell function by modulating the expression of activating receptors and cytolytic activity. Cancer Res. 2012;72(6):1407-15.

87. Yin T, Wang G, He S, Liu Q, Sun J, Wang Y. Human cancer cells with stem cell-like phenotype exhibit enhanced sensitivity to the cytotoxicity of IL-2 and IL-15 activated natural killer cells. Cell Immunol. 2016:300:41-5.

88. Pietra G, Manzini C, Vitale M, Balsamo M, Ognio E, Boitano M, et al. Natura killer cells kill human melanoma cells with characteristics of cancer stem cells. Int Immunol. 2009;21(7):793-801.

89. Ames E, Canter RJ, Grossenbacher SK, Mac S, Chen M, Smith RC, et al. NK cells preferentially target tumor cells with a cancer stem cell phenotype. J Immunol. 2015;195(8):4010-9.

90. Boiko AD, Razorenova OV, van de Rijn M, Swetter SM, Johnson DL, Ly DP, et al. Human melanoma-initiating cells express neural crest nerve growth factor receptor CD271. Nature. 2010;466(7302):133-7.

91. Furuta J, Inozume T, Harada K, Shimada S. CD271 on melanoma cell is an IFN- $\gamma$-inducible immunosuppressive factor that mediates downregulation of melanoma antigens. J Invest Dermatol. 2014;134(5):1369-77.

92. Gedye C, Quirk J, Browning J, Svobodová S, John T, Sluka P, et al. Cancer/ testis antigens can be immunological targets in clonogenic CD133 melanoma cells. Cancer Immunol Immunother. 2009;58(10):1635-46.

93. Koshio J, Kagamu H, Nozaki K, Saida Y, Tanaka T, Shoji S, et al. DEAD/H (AspGlu-Ala-Asp/His) box polypeptide 3, X-linked is an immunogenic target of cancer stem cells. Cancer Immunol Immunother. 2013;62(10):1619-28.

94. Tuccitto A, Tazzari M, Beretta V, Rini F, Miranda C, Greco A, et al. Immunomodulatory factors control the fate of melanoma tumor initiating cells. Stem Cells. 2016; doi:10.1002/stem.2413.

95. Kudo-Saito C, Shirako H, Takeuchi T, Kawakami Y. Cancer metastasis is accelerated through immunosuppression during snail-induced EMT of cancer cells. Cancer Cell. 2009:15(3):195-206.

96. Khalkhali-Ellis Z, Kirschmann DA, Seftor EA, Gilgur A, Bodenstine TM, Hinck $A P$, et al. Divergence(s) in nodal signaling between aggressive melanoma and embryonic stem cells. Int J Cancer. 2015;136(5):E242-51.

97. Rappa G, Anzanello F, Lorico A. Ethanol induces upregulation of the nerve growth factor receptor CD271 in human melanoma cells via nuclear factorKB activation. Oncol Lett. 2015:10(2):815-21.

98. Reya T, Clevers H. Wnt signalling in stem cells and cancer. Nature. 2005; 434(7035):843-50

99. Geng L, Cuneo KC, Cooper MK, Wang H, Sekhar K, Fu A, et al. Hedgehog signaling in the murine melanoma microenvironment. Angiogenesis. 2007; 10(4):259-67. 
100. Santini R, Vinci MC, Pandolfi S, Penachioni JY, Montagnani V, Olivito B, et al. Hedgehog-GLI signaling drives self-renewal and tumorigenicity of human melanoma-initiating cells. Stem Cells. 2012;30(9):1808-18.

101. Pandolfi S, Montagnani V, Lapucci A, Stecca B. HEDGEHOG/GLI-E2F1 axis modulates iASPP expression and function and regulates melanoma cell growth. Cell Death Differ. 2015;22(12):2006-19.

102. Tiwary $\mathrm{S}, \mathrm{Xu} \mathrm{L}$. FRIZZLED7 is required for tumor inititation and metastatic growth of melanoma cells. PLoS One. 2016;11(1):e0147638.

103. Artavanis-Tsakonas S, Rand MD, Lake RJ. Notch signaling: cell fate control and signal integration in development. Science. 1999;284(5415):770-6.

104. Kaushik G, Venugopal A, Ramamoorthy P, Standing D, Subramaniam D, Umar S. Honokiol inhibits melanoma stem cells by targeting notch signaling. Mol Carcinog. 2015;54(12):1710-21.

105. Lin X, Sun B, Zhu D, Zhao X, Sun R, Zhang Y, et al. Notch4+ cancer stemlike cells promote the metastatic and invasive ability of melanoma. Cancer Sci. 2016;107(8):1079-91.

106. Ramakrishnan G, Davaakhuu G, Chung WC, Zhu H, Rana A, Filipovic A, et al. AKT and 14-3-3 regulate Notch4 nuclear localization. Sci Rep. 2015;5:8782.

107. Balint K, Xiao M, Pinnix CC, Soma A, Veres I, Juhasz I, et al. Activation of Notch1 signaling is required for $\beta$-catenin-mediated human primary melanoma progression. J Clin Invest. 2005;115(11):3166-76.

108. Gao H, Chakraborty G, Zhang Z, Akalay I, Gadiya M, Gao Y, et al. Multi-organ site metastatic reactivation mediated by non-canonical discoidin domain receptor 1 signaling. Cell. 2016;166(1):47-62.

109. Peretz Y, Wu H, Patel S, Bellacosa A, Katz RA. Inhibitor of DNA Binding 4 (ID4) is highly expressed in human melanoma tissues and may function to restrict normal differentiation of melanoma cells. PLoS One. 2015;10(2): e0116839.

110. Touil Y, Zuliani T, Wolowczuk I, Kuranda K, Prochazkova J, Andrieux J, et al. The PI3KAKT signaling pathway controls the quiescence of the lowRhodamine123-retention cell compartment enriched for melanoma stem cell activity. Stem Cells. 2013;31(4):641-51.

111. Ostyn P, El Machhour R, Begard S, Kotecki N, Vandomme J, Flamenco P, et al. Transient TNF regulates the self-renewing capacity of stem-like labelretaining cells in sphere and skin equivalent models of melanoma. Cell Commun Signal. 2014;12:52.

112. Keyes WM, Pecoraro M, Aranda V, Vernersson-Lindahl E, Li W, Vogel H, et al. $\Delta \mathrm{Np63a}$ is an oncogene that targets chromatin remodeler Lsh to drive skin stem cell proliferation and tumorigenesis. Cell Stem Cell. 2011;8(2):164-76.

113. Sen T, Sen N, Brait M, Begum S, Chatterjee A, Hoque MO, et al. $\Delta N p 63 a$ confers tumor cell resistance to cisplatin through the AKT1 transcriptional regulation. Cancer Res. 2011;71(3):1167-76.

114. Scadden DT. The stem-cell niche as an entity of action. Nature. 2006; 441(7097):1075-9.

115. Rao G, Wang H, Li B, Huang L, Xue D, Wang X, et al. Reciprocal interactions between tumor-associated macrophages and CD44-positive cancer cells via osteopontin/CD44 promote tumorigenicity in colorectal cancer. Clin Cancer Res. 2013;19(4):785-97

116. Kale S, Raja R, Thorat D, Soundararajan G, Patil TV, Kundu GC. Osteopontin signaling upregulates cyclooxygenase-2 expression in tumor-associated macrophages leading to enhanced angiogenesis and melanoma growth via a9ß1 integrin. Oncogene. 2014;33(18):2295-306.

117. Harris AL. Hypoxia-a key regulatory factor in tumour growth. Nat Rev Cancer. 2002;2(1):38-47.

118. Hanna SC, Krishnan B, Bailey ST, Moschos SJ, Kuan PF, Shimamura T, et al. HIF1a and HIF2a independently activate SRC to promote melanoma metastases. J Clin Invest. 2013;123(5):2078-93.

119. Raja R, Kale S, Thorat D, Soundararajan G, Lohite K, Mane A, et al. Hypoxiadriven osteopontin contributes to breast tumor growth through modulation of HIF1a-mediated VEGF-dependent angiogenesis. Oncogene. 2014;33(16):2053-64

120. Calvani M, Bianchini F, Taddei ML, Becatti M, Giannoni E, Chiarugi P, et al. Etoposide-Bevacizumab a new strategy against human melanoma cells expressing stem-like traits. Oncotarget. 2016; doi:10.18632/oncotarget.9939.

121. Yamada K, Uchiyama A, Uehara A, Perera B, Ogino S, Yokoyama Y, et al. MFG-E8 drives melanoma growth by stimulating mesenchymal stromal cellinduced angiogenesis and M2 polarization of tumor-associated macrophages. Cancer Res. 2016;76(14):4283-92.

122. Ono S, Oyama T, Lam S, Chong K, Foshag LJ, Hoon DS. A direct plasma assay of circulating microRNA-210 of hypoxia can identify early systemic metastasis recurrence in melanoma patients. Oncotarget. 2015;6(9):7053-64.
123. Tavazoie SF, Alarcón C, Oskarsson T, Padua D, Wang Q, Bos PD, et al. Endogenous human microRNAs that suppress breast cancer metastasis. Nature. 2008;451(7175):147-52.

124. Ma L, Teruya-Feldstein J, Weinberg RA. Tumour invasion and metastasis initiated by microRNA-10b in breast cancer. Nature. 2007;449(7163):682-8.

125. Pencheva N, Tran H, Buss C, Huh D, Drobnjak M, Busam K, et al. Convergent multi-miRNA targeting of ApoE drives LRP1/LRP8-dependent melanoma metastasis and angiogenesis. Cell. 2012;151(5):1068-82.

126. Zhang Z, Zhang S, Ma P, Jing Y, Peng H, Gao WQ, et al. Lin28B promotes melanoma growth by mediating a microRNA regulatory circuit. Carcinogenesis. 2015;36(9):937-45.

127. Noman MZ, Buart S, Romero P, Ketari S, Janji B, Mari B, et al. Hypoxiainducible miR-210 regulates the susceptibility of tumor cells to lysis by cytotoxic T cells. Cancer Res. 2012;72(18):4629-41.

128. Wozniak M, Sztiller-Sikorska M, Czyz M. Diminution of miR-340-5p levels is responsible for increased expression of $A B C B 5$ in melanoma cells under oxygen-deprived conditions. Exp Mol Pathol. 2015;99(3):707-16.

129. Dou J, He XF, Cao WH, Zhao FS, Wang XY, Liu YR, et al. Overexpression of microRna-200c in CD44 + CD133+ CSCs inhibits the cellular migratory and invasion as well as tumorigenicity in mice. Cell Mol Biol (Noisy-le-Grand). 2013;Suppl 59:OL1861-8.

130. Zhang P, Bai H, Liu G, Wang H, Chen F, Zhang B, et al. MicroRNA-33b, upregulated by EF24, a curcumin analog, suppresses the epithelial-tomesenchymal transition (EMT) and migratory potential of melanoma cells by targeting HMGA2. Toxicol Lett. 2015;234(3):151-61.

131. Subramani A, Alsidawi S, Jagannathan S, Sumita K, Sasaki AT, Aronow B, et al. The brain microenvironment negatively regulates miRNA-768-3p to promote K-ras expression and lung cancer metastasis. Sci Rep. 2013;3:2392.

132. Kohlhapp FJ, Mitra AK, Lengyel E, Peter ME. MicroRNAs as mediators and communicators between cancer cells and the tumor microenvironment. Oncogene. 2015;34(48):5857-68.

133. Forloni M, Dogra SK, Dong Y, Conte Jr D, Ou J, Zhu LJ, et al. miR-146a promotes the initiation and progression of melanoma by activating Notch signaling. Elife. 2014;3:e01460.

134. Meier C, Hardtstock P, Joost S, Alla V, Pützer BM. p73 and IGF1R regulate emergence of aggressive cancer stem-like features via miR-885-5p control. Cancer Res. 2016;76(2):197-205.

135. Liu S, Kumar SM, Lu H, Liu A, Yang R, Pushparajan A, et al. MicroRNA-9 upregulates E-cadherin through inhibition of NF-KB1-Snail1 pathway in melanoma. J Pathol. 2012;226(1):61-72.

136. Bao S, Wu Q, McLendon RE, Hao Y, Shi Q, Hjelmeland AB, et al. Glioma stem cells promote radioresistance by preferential activation of the DNA damage response. Nature. 2006;444(7120):756-60.

137. Song H, Su X, Yang K, Niu F, Li J, Song J, et al. CD20 antibody-conjugated immunoliposomes for targeted chemotherapy of melanoma cancer initiating cells. J Biomed Nanotechnol. 2015;11(11):1927-46.

138. Garbe C. Chemotherapy and chemoimmunotherapy in disseminated malignant melanoma. Melanoma Res. 1993;3(4):291-9.

139. Biasco G, Pantaleo MA, Casadei S. Treatment of brain metastases of malignant melanoma with temozolomide. N Engl J Med. 2001;345(8):621-2.

140. Flaherty LE, Atkins M, Sosman J, Weiss G, Clark JI, Margolin K, et al. Outpatient biochemotherapy with interleukin-2 and interferon alfa-2b in patients with metastatic malignant melanoma: results of two phase II cytokine working group trials. J Clin Oncol. 2001;19(13):3194-202.

141. Hovinga KE, Shimizu F, Wang R, Panagiotakos G, Van Der Heijden M, Moayedpardazi $\mathrm{H}$, et al. Inhibition of notch signaling in glioblastoma targets cancer stem cells via an endothelial cell intermediate. Stem Cells. 2010;28(6):1019-29.

142. Bar EE, Chaudhry A, Lin A, Fan X, Schreck K, Matsui W, et al. Cyclopaminemediated hedgehog pathway inhibition depletes stem-like cancer cells in glioblastoma. Stem Cells. 2007;25(10):2524-33.

143. Curtin JC, Lorenzi MV. Drug discovery approaches to target Wnt signaling in cancer stem cells. Oncotarget. 2010;1(7):552-66.

144. Adorno-Cruz V, Kibria G, Liu X, Doherty M, Junk DJ, Guan D, et al. Cancer stem cells: targeting the roots of cancer, seeds of metastasis, and sources of therapy resistance. Cancer Res. 2015;75(6):924-9.

145. Mukherjee N, Reuland SN, Lu Y, Luo Y, Lambert K, Fujita M, et al. Combining a BCL2 inhibitor with the retinoid derivative fenretinide targets melanoma cells including melanoma initiating cells. J Invest Dermatol. 2015;135(3):842-50.

146. Mukherjee N, Schwan JV, Fujita M, Norris DA, Shellman YG. Alternative treatments for melanoma: targeting BCL-2 family members to de-bulk and kill cancer stem cells. J Invest Dermatol. 2015;135(9):2155-61. 
147. Mukherjee N, Lu Y, Almeida A, Lambert K, Shiau CW, Su JC, et al. Use of a MCL-1 inhibitor alone to de-bulk melanoma and in combination to kill melanoma initiating cells. Oncotarget. 2016; doi:10.18632/oncotarget.8695.

148. El-Khattouti A, Sheehan NT, Monico J, Drummond HA, Haikel Y, Brodell RT, et al. $\mathrm{CD} 133^{+}$melanoma subpopulation acquired resistance to caffeic acid phenethyl ester-induced apoptosis is attributed to the elevated expression of ABCB5: Significance for melanoma treatment. Cancer Lett. 2015;357(1):83-104.

149. Dai W, Zhou J, Jin B, Pan J. Class III-specific HDAC inhibitor Tenovin-6 induces apoptosis, suppresses migration and eliminates cancer stem cells in uveal melanoma. Sci Rep. 2016;6:22622. doi:10.1038/srep22622.

150. Lu L, Tao H, Chang AE, Hu Y, Shu G, Chen Q, et al. Cancer stem cell vaccine inhibits metastases of primary tumors and induces humoral immune responses against cancer stem cells. Oncoimmunology. 2015;4(3):e990767.

151. Soldevilla MM, Villanueva H, Casares N, Lasarte JJ, Bendandi M, Inoges S, et al. MRP1-CD28 bi-specific oligonucleotide aptamers: target costimulation to drug-resistant melanoma cancer stem cells. Oncotarget. 2016;7(17):2318296.

152. Shen H, Shi S, Zhang Z, Gong T, Sun X. Coating solid lipid nanoparticles with hyaluronic acid enhances antitumor activity against melanoma stemlike cells. Theranostics. 2015;5(7):755-71.

153. Zhang $X$, Cheng $X$, Lai $Y$, Zhou Y, Cao W, Hua ZC. Salmonella VNP20009mediated RNA interference of ABCB5 moderated chemoresistance of melanoma stem cell and suppressed tumor growth more potently. Oncotarget. 2016;7(12):14940-50.

154. Jordan CT. Cancer Stem Cells: Controversial or Just Misunderstood? Cell Stem Cell. 2009:4(3):203-5.

155. Quintana E, Shackleton M, Foster HR, Fullen DR, Sabel MS, Johnson TM, et al. Phenotypic heterogeneity among tumorigenic melanoma cells from patients that is reversible and not hierarchically organized. Cancer Cell. 2010;18(5):510-23.

156. Quintana E, Shackleton M, Sabel MS, Fullen DR, Johnson TM, Morrison SJ. Efficient tumour formation by single human melanoma cells. Nature. 2008; 456(7222):593-8

157. Shakhova O, Sommer L. Testing the cancer stem cell hypothesis in melanoma: the clinics will tell. Cancer Lett. 2013;338(1):74-81.

158. Joshi P, Kooshki M, Aldrich W, Varghai D, Zborowski M, Singh AD, et al. Expression of natural killer cell regulatory microRNA by uveal melanoma cancer stem cells. Clin Exp Metastasis. 2016;33(8):829-38.

159. Prokopi M, Kousparou CA, Epenetos AA. The secret role of microRNAs in cancer stem cell development and potential therapy: A Notch-pathway approach. Front Oncol. 2015:4:389. doi:10.3389/fonc.2014.00389.

160. Sellerio AL, Ciusani E, Ben-Moshe NB, Coco S, Piccinini A, Myers CR, et al. Overshoot during phenotypic switching of cancer cell populations. Sci Rep. 2015:5:15464. doi:10.1038/srep15464.

\section{Submit your next manuscript to BioMed Central and we will help you at every step:}

- We accept pre-submission inquiries

- Our selector tool helps you to find the most relevant journal

- We provide round the clock customer support

- Convenient online submission

- Thorough peer review

- Inclusion in PubMed and all major indexing services

- Maximum visibility for your research

Submit your manuscript at www.biomedcentral.com/submit 